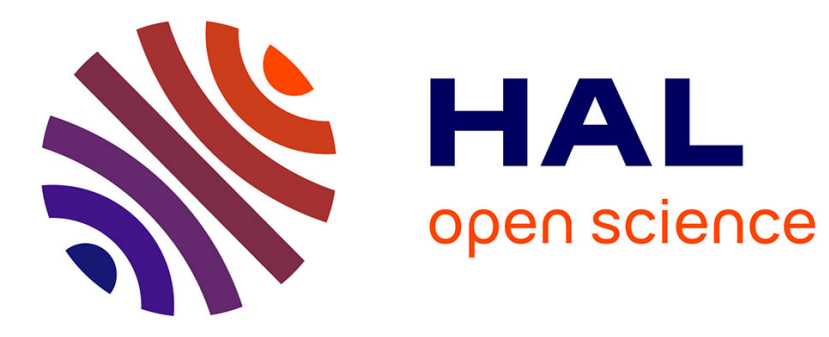

\title{
Bio-based glyco-bolaamphiphile forms a temperature-responsive hydrogel with tunable elastic properties
}

Niki Baccile, Lisa Van Renterghem, Patrick Le Griel, Guylaine Ducouret, Martha Brennich, Viviana Cristiglio, Sophie L. K. W. Roelants, Wim Soetaert

\section{To cite this version:}

Niki Baccile, Lisa Van Renterghem, Patrick Le Griel, Guylaine Ducouret, Martha Brennich, et al.. Biobased glyco-bolaamphiphile forms a temperature-responsive hydrogel with tunable elastic properties. Soft Matter, 2018, 14 (38), pp.7859 - 7872. 10.1039/C8SM01167B . hal-01925375

\section{HAL Id: hal-01925375 https://hal.sorbonne-universite.fr/hal-01925375}

Submitted on 16 Nov 2018

HAL is a multi-disciplinary open access archive for the deposit and dissemination of scientific research documents, whether they are published or not. The documents may come from teaching and research institutions in France or abroad, or from public or private research centers.
L'archive ouverte pluridisciplinaire HAL, est destinée au dépôt et à la diffusion de documents scientifiques de niveau recherche, publiés ou non, émanant des établissements d'enseignement et de recherche français ou étrangers, des laboratoires publics ou privés. 


\title{
Bio-based glyco-bolaamphiphile forms a temperature-responsive hydrogel with tunable elastic properties
}

\author{
Niki Baccile, ${ }^{\mathrm{a} *}$ Lisa Van Renterghem, ${ }^{\mathrm{b}}$ Patrick Le Griel, ${ }^{\mathrm{a}}$ Guylaine Ducouret, ${ }^{\mathrm{c}}$ Martha \\ Brennich, ${ }^{\text {d Viviana Cristiglio, }}{ }^{\text {e Sophie Roelants, }}{ }^{\text {b,f }}$ Wim Soetaert ${ }^{\text {b }}$ \\ a Sorbonne Université, Centre National de la Recherche Scientifique, Laboratoire de Chimie de la \\ Matière Condensée de Paris, LCMCP, F-75005 Paris, France \\ ${ }^{\mathrm{b}}$ Ghent University, Centre for Industrial Biotechnology and Biocatalysis (InBio.be), Faculty of \\ Bioscience Engineering, Coupure Links 653, Ghent, Oost-Vlaanderen, BE 9000 \\ c Laboratoire Sciences et Ingénierie de la Matière Molle, CNRS UMR 7615, ESPCI Paris, PSL \\ Research University, 10 rue Vauquelin, F-75231 Paris cedex 05, France \\ ${ }^{\mathrm{d}}$ European Molecular Biology Laboratory, Synchrotron Crystallography Group, 71 Avenue des \\ Martyrs, 38042 Grenoble, France \\ e Institut Laue-Langevin, Grenoble, Beamline D16, Cedex 9, 38042, Grenoble, France \\ ${ }^{\mathrm{f}}$ Bio Base Europe Pilot Plant, Rodenhuizekaai 1, Ghent, Oost-Vlaanderen, BE 9000
}

\begin{abstract}
:
A bio-based glycolipid bolaamphiphile (glyco-bolaamphiphile) has recently been recently produced (Van Renterghem et al., Biotechnol Bioeng., 2018, 115, 1195-1206) at a gram scale by using the genetically-engineered $S$. bombicola strain $\Delta a t \Delta$ sble $\Delta$ fao1. The glyco-bolaamphiphile bears two symmetrical sophorose headgroups at the extremities of a C16:0 ( $\omega$-1 hydroxylated palmitic alcohol) spacer. Its atypical structure has been obtained by redesigning the $S$. bombicola strain $\Delta a t \Delta s b l e$, producing non-symmetrical glyco-bolaamphiphile, with an additional knock out ( $\Delta$ fao1) and feeding this new strain with fatty alcohols. The molecular structure of the glycobolaamphiphile is obtained by feeding the new strain a saturated C16 substrate (hexadecanol), which enables the biosynthesis of bolaform glycolipids. In this work, we show that the bio-based glyco-bolaamphiphile readily forms a hydrogel in water at room temperature, and that the hydrogel formation depends on the formation of self-assembled fibers. Above $28^{\circ} \mathrm{C}$, the molecules undergo a gel-to-sol transition, which is due to a fiber-to-micelles phase change. We provide a quantitative description of the Self-Assembled Fibrillar Network (SAFiN) hydrogel formed by the glycobolaampiphile. We identify the sol-gel transition temperature, the gelling time, and minimal gel
\end{abstract}


concentration; additionally, we explore the fibrillation mechanism as a function of time and temperature and determine the activation energy of the micelle-to-fiber phase transition. These parameters allow controlling the elastic properties of the glyco-bolaamphiphile hydrogel: at $3 \mathrm{wt} \%$ and $25^{\circ} \mathrm{C}$, the elastic modulus $\mathrm{G}^{\prime}$ is above the $\mathrm{kPa}$ range, while at $5^{\circ} \mathrm{C}, \mathrm{G}^{\prime}$ can be tuned between $100 \mathrm{~Pa}$ and $20 \mathrm{kPa}$, by controlling the undercooling protocol.

\section{Introduction:}

Flory classified hydrogels as lamellar and particulate structures, but also physical and covalent polymer networks, ${ }^{1}$ are studied in depth for tissue engineering, ${ }^{2-6}$ drug release, ${ }^{7}$ biomedical injectable fillers, ${ }^{8}$ and other more advanced applications, like art conservation, ${ }^{9}$ confined reaction vessels ${ }^{10}$ and ionic conductors. ${ }^{11}$ Flory's classification has been challenged in the past two decades by new types of gels, namely molecular gels. These are obtained by the selfassembly of Low Molecular Weight Gelators (LMWG) into a Self-Assembled Fibrillar Network (SAFiN). ${ }^{12}$ These soft materials are highly promising: gelation is reversible due to their stimuliresponsiveness (towards $\mathrm{pH}, \mathrm{T}$, ionic force, light, mechanic ...), which is an advantage compared to most polymer-based hydrogels, for targeted applications in the biomedical field, ${ }^{12-16}$ in wastewater treatment ${ }^{17}$ and even antibacterial use. ${ }^{18}$

Most LMWG are a combination of the $\pi-\pi$ stacking and hydrogen bonding of functional groups in the same molecule, e.g., fluorenylmethoxycarbonyl (Fmoc), L-cystine or amino acid derivatives. Through molecular engineering one can obtain rapid (in the order of seconds up to few minutes) gelation with elastic moduli in the $10 \mathrm{kPa}-10^{2} \mathrm{kPa}$ range, for concentrations in the $\mathrm{mM}$ range or even below. ${ }^{19-22}$ However, engineered molecular systems often require complex organic synthesis involving multi-step protection/deprotection processes and, in any case, the smartest molecular design does not guarantee success in terms of hydrogelation, which is often driven by serendipity ${ }^{12,19}$ and more down-to-earth physico-chemical parameters like temperature, heating/cooling rate, $\mathrm{pH}$, etc... ${ }^{23-31}$

Sustainability in the development of hydrogels is becoming a popular approach, ${ }^{17}$ especially for potential applications in cosmetics, food science and biomedicine. ${ }^{16}$ Glycosylated LMWG have shown some nice examples of hydrogel-forming systems, ${ }^{32-35}$ exhibiting elastic moduli above $10 \mathrm{kPa}^{21}$. Such compounds are derived from sugars, which are widely available and renewable biobased molecules, and can also be obtained from side stream process and 
lignocellulosic biomass. ${ }^{21,32-34,36-39}$ However, this class of compounds is still obtained through sugar organic chemistry, which is notoriously time and energy-consuming due to the lengthy protection/deprotection procedures. Instead of developing a new complex chemical synthesis, we have focused our efforts on bio-based-hydrogels produced by a microbial fermentation approach.

Fermented glycosylated lipids, a class of molecules often referred to as biosurfactants, are historically developed for biodegradable detergent formulations, ${ }^{40,41}$ even if recent developments in this field show a much higher potential. ${ }^{42-46}$ Despite the large benefit of this approach (biocompatibility, biodegradability) one must face limited structural heterogeneity. To overcome this problem a strong effort in terms of genetic engineering ${ }^{47}$ has shown that molecular variability, ${ }^{48}$ higher uniformity and purity, production scale-up and process development ${ }^{49-51}$ can be obtained by new strains. ${ }^{52-54}$ We have recently shown that the fibrillation properties in water of acidic sophorolipids ${ }^{55,56,57}$ and hydrolyzed cellobioselipids, ${ }^{58}$ but their gelation properties are not demonstrated so far. Here, we illustrate the hydrogel properties of a new generation of symmetrical bolaform sophoroside ${ }^{44}$ biosurfactant. The common carboxylic acid present in sophorolipids is replaced with an additional sophorose unit ${ }^{52}$ and palmitic alcohol is employed, instead of standard fatty acids, as substrate to generate the chemically-stable $\omega$ - 1 hydroxylated C16:0 symmetrical bolaform sophoroside (sBola C16:0 SS, Figure 1a). ${ }^{48}$ This compound was produced at gram-scale with the genetically-engineered $S$. bombicola strain $\Delta a t \Delta s b l e \Delta f a o 1$, derived from the $S$. bombicola strain $\Delta a t \Delta s b l e$ (producing non-symmetrical bola acidic sophorolipids) with an additional knock out $(\Delta f a 01)$.

We assume that this new compound has similar fibrillation properties as found in acidic sophoro- and cellobioselipids, but with a stronger tendency to form an extended H-bonding network, which could enhance hydrogel formation, a property which is not reported for the acidic compounds, yet. In addition, the loss of the carboxylic acid confers a better stability towards $\mathrm{pH} .{ }^{44}$ In this work, we combine Small Angle X-ray Scattering (SAXS), cryo-Transmission Electron Microscopy (cryo-TEM), time and temperature-resolved rheology and solution ${ }^{1} \mathrm{H}$ Nuclear Magnetic Resonance (NMR) to show that sBola C16:0 SS forms a SAFiN hydrogel at concentrations as low as $1 \mathrm{wt} \%$, with an elastic modulus which can be tuned between $100 \mathrm{~Pa}$ and $20 \mathrm{kPa}$ under controlled conditions: these properties are comparable with hydrogels obtained using synthetic gelators. ${ }^{19-22}$ This work consists of a first thorough study of the aqueous self-assembly and hydrogel-forming properties of a genetically-engineered, bio-based, glycolipid; considering 
the potential biocompatibility toward cells (red blood count test) for this class of compounds, ${ }^{48}$ we open new ways for microbially-derived soft materials in the field of biomedical and health-care applications.

\section{Materials and Methods:}

Products. Symmetrical bola sophoroside (SS) with a C16:0 backbone (sBola C16:0 SS) were produced as described by Van Renterghem et al. using S. bombicola strain $\Delta a t \Delta$ sble $\Delta$ fao $1 .^{48}$ The production occurred in shake flask cultures and purification is performed as described by the same authors. Chemical structure by 1D and 2D NMR and purification of sBola C16:0 SS has also been described in ref ${ }^{48}$. HPLC-ELSD and LC-MS data, confirming the purity of the product, are reported and commented in Figure S 1.

Self-assembly. sBola C16:0 SS is dissolved in milliQ grade water at the desired concentration at $25^{\circ} \mathrm{C}$ and strongly vortexed for about $30 \mathrm{~s}$ to $1 \mathrm{~min}$ until the powder has entirely dissolved and a translucent colloidal suspension is obtained. The apparent viscosity of the solution is quite low after vortexing, but it slowly increases with time. In a second set of experiments, the as-prepared sBola C16:0 SS solution is heated above $30^{\circ} \mathrm{C}$ (please, refer to text for more details) for five minutes until the solution becomes clear. The temperature is then lowered to $25^{\circ} \mathrm{C}$ or below. This procedure is detailed in the section titled Temperature-dependent mechanical properties of the hydrogel.

Small Angle $X$-ray Scattering (SAXS): SAXS experiments are performed at $25^{\circ} \mathrm{C}$ immediately after sample preparation on the BioSAXS BM29 beamline at the ESRF synchrotron facility (Grenoble, France) using $12.5 \mathrm{KeV}$ energy and a sample-to-detector distance of $2.867 \mathrm{~m}$, imposed by the beamline standard configuration. The energy is calibrated by measuring the $\mathrm{L}_{\mathrm{I}}$ and $\mathrm{L}_{\mathrm{III}}$ edges of platinum and the sample-to-detector distance is determined using silver behenate $\left(\mathrm{d}_{\text {ref }}=58.38\right.$ $\AA$ ). ${ }^{59,60}$ For this experiment, we employ the automatic sample changer for liquids using the 96-well plates and about $100 \mu \mathrm{L}$ of each sample. ${ }^{61}$ The liquid sample is automatically loaded into a 1.8 mm quartz glass capillary and ten acquisitions of $1 \mathrm{~s}$ each are taken as the sample passes the beam. Individual frames are manually controlled for systematic changes and averaged for better statistics if none are found. Eventual changes can be either due to intrinsic sample heterogeneity or radiation damage. The signal of the Pilatus $1 \mathrm{M}$ 2-D detector, used to record the data, is integrated azimuthally with PyFAI to obtain the $I(q)$ vs. $q$ spectrum $(q=4 \pi \sin \theta / \lambda$, where $2 \theta$ is the 
scattering angle) after masking systematically wrong pixels and the beam stop shadow. ${ }^{62}$ Absolute intensity units were determined by measuring the scattering signal of water $\left(0.0163 \mathrm{~cm}^{-1}\right)$. Small Angle Neutron Scattering (SANS): SANS was performed at the Institut Laue-Langevin (ILL) on the D16 beamline using a neutron wavelength, $\lambda=4.5 \AA$, a sample-to-detector distance, $\mathrm{d}=955$ $\mathrm{mm}$, sample and detector rotation angles: $\omega=5.5^{\circ}$ and $2 \theta=11^{\circ}$, and an acquisition time $=60 \mathrm{~min}$. Neutron absorber: Boron Carbide (B4C), thickness of quartz Hellma cells: $1 \mathrm{~mm} .{ }^{63}$ The sample is thermalized at $25^{\circ} \mathrm{C}$ and $40^{\circ} \mathrm{C}$. $\mathrm{D}_{2} \mathrm{O}$ is used as solvent for the self-assembly experiments. Direct beam, empty cell and $\mathrm{H}_{2} \mathrm{O}$ are also recorded. The background corresponded with $99.9 \% \mathrm{D}_{2} \mathrm{O}$. Direct beam, empty cell and $\mathrm{H}_{2} \mathrm{O}$ were also recorded for both spectrometers. The background sample $\left(\mathrm{D}_{2} \mathrm{O}\right)$ signal was subtracted from the experimental data. Data treatment is done with the home-made software package provided at the beamline. Absolute values of the scattering intensity are obtained from the direct determination of the number of neutrons in the incident beam and the detector cell solid angle. The 2-D raw data were corrected for the ambient background and empty cell scattering and normalized to yield an absolute scale (cross section per unit volume) by the neutron flux on the samples. The data were then circularly averaged to yield the 1-D intensity distribution, I(q).

Fourier Transform InfraRed spectroscopy (FTIR): FTIR experiments have been done in the ATR mode using a Perkin Elmer Spectrum 400 instrument.

Rheology: viscoelastic measurements were carried out on a stress controlled rheometer Haake RS 600 equipped with a sandblasted, stainless steel cone and plate geometry (diameter $35 \mathrm{~mm}$, angle $2^{\circ}$, truncation $104 \mathrm{~mm}$ ). First, the sample was submitted to a short stress sweep at $1 \mathrm{~Hz}$ to determine the viscoelastic regime. In order to preserve the sample, the stress sweep was stopped before the end of the viscoelastic plateau. Next, the frequency sweep was performed covering a frequency (f) range from $1.510^{-2}$ to $15 \mathrm{~Hz}$. The elastic $\left(G^{\prime}\right)$ and loss $\left(G^{\prime \prime}\right)$ moduli were measured in the linear viscoelastic regime. In order to prevent the sample from drying, the geometry is protected by a homemade device, although drying could occur for experimental time longer than about $20 \mathrm{~h}-24$ h. Measurements were repeated on several samples to check the reproducibility. Cryo-Transmission Electron Microscopy (TEM): cryo-TEM was performed on a sample at a concentration of $1 \mathrm{wt} \%$ fresh from preparation and after rest over one night. A FEI Tecnai 120 twin microscope operating at $120 \mathrm{kV}$ equipped with a Gatan Orius CCD numeric camera is used for cryo-TEM experiments. The sample holder is a Gatan Cryoholder (Gatan 626DH, Gatan). 
DigitalMicrograph $^{\mathrm{TM}}$ software is used for image acquisition. Cryofixation is performed on a homemade cryo-fixation device. The solutions is deposited on a glow discharded holey carbon coated TEM copper grid (Quantifoil R2/2, Germany). Excess solution is removed from the grid, which is immediately plunged into liquid ethane at $-180^{\circ} \mathrm{C}$ before transferring it into liquid nitrogen. All grids are kept at liquid nitrogen temperature throughout all experimentation. Postacquisition image treatment has been done with $\mathrm{Fiji}^{64}{ }^{64}$ available at the developer's website (https://imagej.net/Fiji) without charge.

Nuclear Magnetic Resonance (NMR): time-resolved ${ }^{1} \mathrm{H}$ solution NMR experiments are acquired on a Bruker Avance III 300 spectrometer using a $5 \mathrm{~mm} 1 \mathrm{H}-\mathrm{X}$ BBFO probe. Number of transient is 16 with $5 \mathrm{~s}$ recycling delay. Experiments are carried out in $\mathrm{D}_{2} \mathrm{O}$ as follows: a $3 \mathrm{wt} \%$ concentrated solution is heated within the NMR probe at $40^{\circ} \mathrm{C}$ during 5 minutes in order to have a sol. Next, temperature is set at $25^{\circ} \mathrm{C}$ or lower (exact values are given for each experiments in the main text); the time-resolved acquisition starts when $\mathrm{T}=25^{\circ} \mathrm{C}$ is reached, where a delay of about $3 \mathrm{~min}$ occurs during temperature variation. A slightly longer delay ( $5 \mathrm{~min}$ ) occurs between $\mathrm{T}=40^{\circ} \mathrm{C}$ and lower temperatures. In any case, such a delay is always taken into account in all time-resolved plots and the zero-time, $\mathrm{t}_{0}$, is systematically taken at $\mathrm{T}=40^{\circ} \mathrm{C}$. This is not important for the kinetic experiments at $\mathrm{T}=25^{\circ} \mathrm{C}$, but it becomes crucial at lower temperatures, where the sol-gel transition occurs during the dead time. Finally, an internal coaxial insert capillary containing a TMSPd4 solution in $\mathrm{D}_{2} \mathrm{O}$ as internal reference is used to calibrate both the chemical shift and intensity variation throughout the experiment. Absolute values of the peak area as a function of time is obtained using the "integration" and "relaxation" moduli of the Topspin ${ }^{\mathrm{TM}} 3.5 \mathrm{pl} 7$ version of the software, while the Full Width at Half Maximun (FWHM) profiles have been automatically obtained by using of DMFit software, available free of charge at the developer's website. ${ }^{65,66} \mathrm{We}$ have observed that phasing problems due to lowering the temperature and phase transition may affect the peak of $\mathrm{H}_{2} \mathrm{O}$. Since this is the most intense peak, poor phasing can affect the baseline in the vicinity of the sugar $\mathrm{C} \underline{H}$ region of sBola C16:0 SS between $3 \mathrm{ppm}$ and $4.5 \mathrm{ppm}$. This unavoidable fact strongly affects the actual value of the peak area. For this reason, we mainly present the time-resolved evolution of the aliphatic peak area, contained between $0.5 \mathrm{ppm}$ and 2.5 ppm. Peak area normalization is performed with respect to the spectrum recorded at $t_{0}$ in the sol phase, which is at $\mathrm{T}=40^{\circ} \mathrm{C}$, when one can detect the entire sBola C16:0 SS population. Finally, the volume of the solution is always kept at $500 \mu \mathrm{L}$ for all the experiments. 
High-Performance Liquid Chromatography (HPLC) coupled to Evaporative Light Scattering Detector (ELSD): HPLC-ELSD analysis is performed with the Agilent 1260 Infinity equipped with an Agilent Zorbax Eclipse Plus C18 column $(4.6 \times 100 \mathrm{~mm}-3.5 \mu \mathrm{m})$ at $40^{\circ} \mathrm{C}$. A flow rate of $1 \mathrm{~mL} / \mathrm{min}$ is applied and a gradient of two solvents (A: $0.05 \%$ acetic acid and B: acetonitrile) is applied using the following method: 0 min: 95\% A and 5\% B, 25 min: 5\% A and 95\% B, 27 min: 5\% A and 95\% B and 30 min: 95\% A and 5\% B.

Liquid Chromatography-Mass Spectrometry (LC-MS): LC-MS analysis is done on a Shimadzu LC-10-AD HPLC system (Shimadzu Europe GmbH, Germany) connected to a quadrupole mass spectrometer Micromass Quattro LC (Waters, Milford, MA). The different components were separated by polarity on a Chromolith Performance RP-18 Endcapped 100-4.6 mm column (Merck $\mathrm{KGaA})$ at $30^{\circ} \mathrm{C}$. The LC-MS method uses a gradient elution based on the same solvents used for HPLC-ELSD analysis (A: $0.05 \%$ acetic acid and B: acetonitrile). During the analysis, a flow rate of $1 \mathrm{~mL} / \mathrm{min}$ was applied. The gradient starts with 5\% B and 95\% A and increases linearly to 95\% $\mathrm{B}$ and 5\% A over the course of 40 minutes. After this, the $95 \% \mathrm{~B}$ and $5 \% \mathrm{~A}$ is held for another 10 minutes, after which this is brought back to $5 \% \mathrm{~B}$ and $95 \% \mathrm{~A}$ in the last 5 minutes (total time per sample is 60 minutes). Molecules are identified by their native molecular masses after ESI (electron spray ionization) without collision.

\section{Results and Discussion}

Hydrogel-forming properties of sBola C16:0 SS.

Upon mixing sBola C16:0 SS with milliQ grade water at room temperature without $\mathrm{pH}$ adjustment, a turbid solution is obtained. Several concentration values between 1 and $10 \mathrm{wt} \%$ were tested, and the obtained solution is generally fluid at any concentration while mixing. However, upon a rest time of few minutes, the viscosity increases, and whatever the concentration, gels are translucid, as shown by the classical inverted tube test shown on Figure 1b. Concentration- and time-dependent rheology (Figure 1c) experiments show that the storage modulus, $\mathrm{G}^{\prime}$, of the solution few minutes after mixing $(\mathrm{t}=0 \mathrm{~h})$ is systematically below $1 \mathrm{~Pa}$ for the $1 \mathrm{wt} \%$ system, which characterizes a fluidic solution, while $\mathrm{G}^{\prime}$ increases at about $10^{3} \mathrm{~Pa}$ for a $10 \mathrm{wt} \%$ solution at $t=0 \mathrm{~h}$. Upon rest overnight $\left(\mathrm{t}=15 \mathrm{~h}\right.$ ), $\mathrm{G}^{\prime}$ strongly increases and it varies between $10^{2} \mathrm{~Pa}$ and $10^{4}$ Pa, respectively, for solutions at $1 \mathrm{wt} \%$ and $10 \mathrm{wt} \%$. The classical gel-like behavior for solutions between $1 \mathrm{wt} \%$ and $5 \mathrm{wt} \%(\mathrm{t}=15 \mathrm{~h})$ is shown in Figure 2. Both elastic modulus $\mathrm{G}^{\prime}$ and loss modulus 
$\mathrm{G}^{\prime \prime}$ are constant, and $\mathrm{G}^{\prime}$ is at least a decade higher than $\mathrm{G}^{\prime \prime}$ on the entire frequency range. The viscoelastic properties of the sample does not depend on the frequency, unlike conventional polymers suspensions ${ }^{67}$ or other low molecular gelators, which display viscous behavior at low frequency. ${ }^{14}$ Typical longer rest times may improve the overall $\mathrm{G}^{\prime}$ value, although this aspect cannot be trustily measured due to water evaporation for a sensibly longer waiting time. The magnitude of $\mathrm{G}^{\prime}$ found for sBola C16:0 SS hydrogel is comparable with standard LMWG found in the literature, where $\mathrm{G}^{\prime} \geq 1 \mathrm{kPa} \cdot{ }^{19,20,21} \mathrm{FmocY}$ (fluorenylmethoxycarbonyl) derivatives are characterized by $\mathrm{G}^{\prime}$ values between $1 \mathrm{kPa}$ and $4 \mathrm{kPa}$ below $2 \mathrm{wt} \%$ at $37^{\circ} \mathrm{C}$ and in a pH range between 6 and 9, MAX1 has $\mathrm{G}^{\prime}$ in the order of $1 \mathrm{kPa}$ at $2 \mathrm{wt} \%, \mathrm{pH} 9$ and $25^{\circ} \mathrm{C}$, ${ }^{19}$ while carbohydrate-based compounds ${ }^{20,21,32,33,36}$ have $\mathrm{G}^{\prime}$ values above $10 \mathrm{kPa}$ in the $1 \mathrm{wt} \%-2 \mathrm{wt} \%$ range.

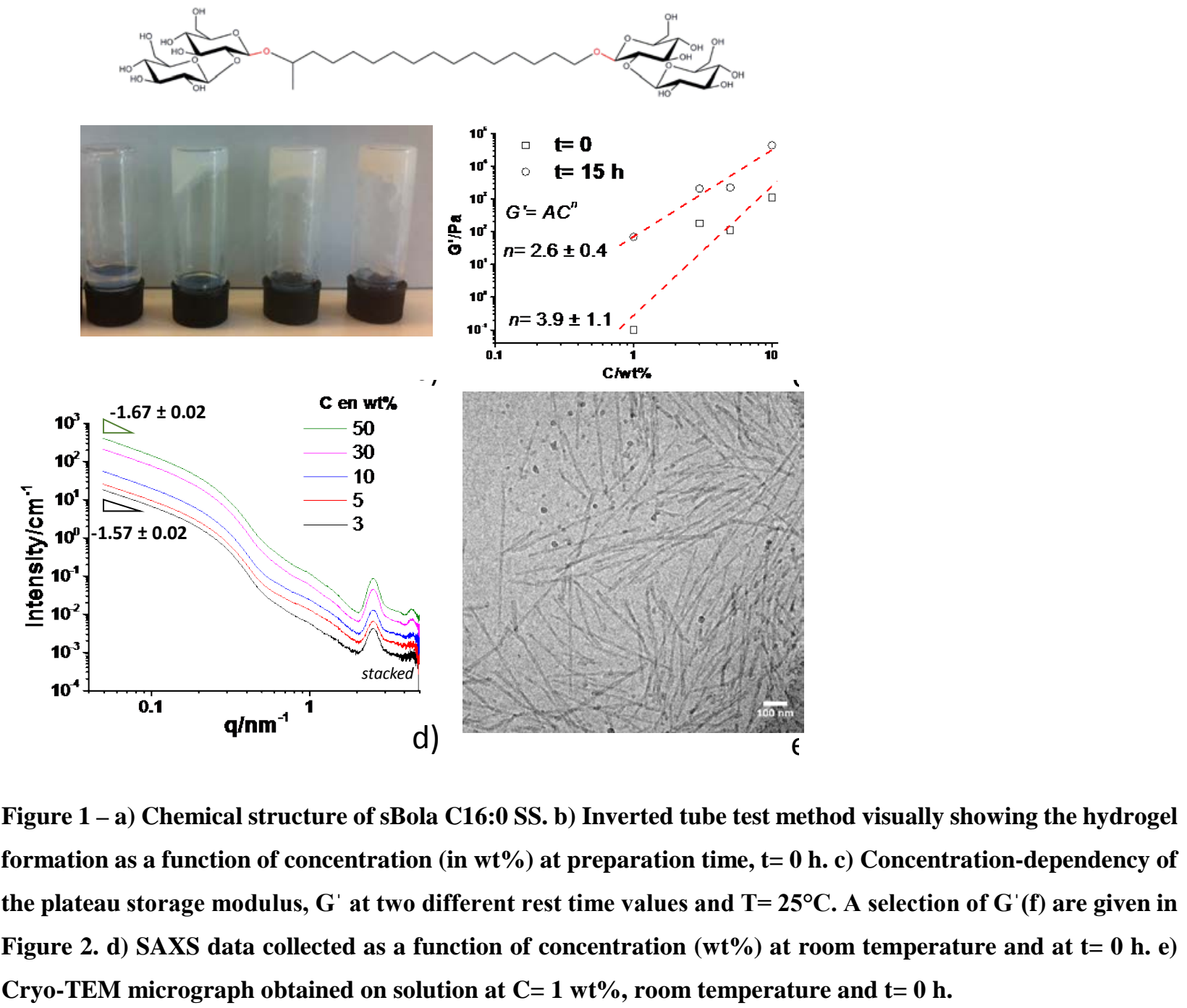


The formation of a stable gel over time is expected due to the self-assembly of sBola in water. Figure 1d and Figure 1e show the nano- and mesoscale structure of sBola C16:0 SS in water, respectively by Small Angle X-ray Scattering (SAXS) and cryo-TEM. Concentration-dependent SAXS experiments performed at $\mathrm{t}=0 \mathrm{~h}$ show a nice scattering signal for all samples between 0.3 and $5 \mathrm{wt} \%$. Whatever the concentration values, the signal looks the same and it is characterized by low-q scattering profile, which is strongly similar to the SAXS pattern of self-assembled ribbons, commonly found for the stearic acid (C18:0) derivative of acidic sophorolipid. ${ }^{55}$ In particular, the power law exponent (slope) measured for our data lies between 1.6 and 1.7; these values are close to 2, generally expected for (helical) ribbons both theoretically and experimentally. ${ }^{55,68,69}$ The small discrepancy between the theoretical and experimental value of the exponent in this system can be attributed to fiber aggregation, as shown before. ${ }^{56}$ Cryo-TEM experiments performed on a $1 \mathrm{wt} \%$ sample at $\mathrm{t}=0 \mathrm{~h}$ (Figure 1e) confirm that the sample is composed of fibers, which are most likely twisted (cross-section below $20 \mathrm{~nm}$ ), as previously described in our own ${ }^{55}$ and other works. ${ }^{70}$ Since we cannot guarantee that all fibers in the systems are twisted, the general term fibers and twisted ribbons will be both used to refer to the fibrillary phase of the sample.

SAXS data also display a broad Bragg diffraction peak at $\mathrm{q}=2.53 \mathrm{~nm}^{-1}$, which corresponds to a correlation distance of $\mathrm{d}=2.48 \mathrm{~nm}$, and it highlights a periodic molecular arrangement of sBola C16:0 SS within each ribbon, as also described for other sophorolipid systems, ${ }^{55}$ and found for other sugar bolaamphiphile-derived fibers. ${ }^{71}$ Since the full-extended size of sBola C16:0 SS is expected to be well above $2.5 \mathrm{~nm}$ (according to the Tanford formula, ${ }^{72}$ the fully extended length of C16 is about $2.1 \mathrm{~nm}$ while the size of one sophorose unit is about $1 \mathrm{~nm}$ ), the inter-lipid distance is then coherent with a tilted arrangement of sBola C16:0 SS, as described for other bolaform glycolipids. $^{71}$ To this regard, the literature is not clear whether the diffraction peak in our SAXS data can be unambiguously attributed to a crystalline or liquid crystalline order within the ribbons ${ }^{73}$ since it is not our intent to solve this matter here, we will simply refer to a Bragg diffraction peak. The attribution of the second diffraction peak at $4.46 \mathrm{~nm}^{-1}(\mathrm{~d}=1.41 \mathrm{~nm})$ is less straightforward: its d-spacing value, which is 1.8 times the first peak, could suggest the presence of a hexagonal packing within the ribbon (expected ratio is $\sqrt{3}$ ). Nonetheless, most studies performed on lipid systems self-assembled in chiral fibers have shown the presence of orthorhombic, triclinic or lamellar packing, instead. ${ }^{74-77}$ Other studies run on self-assembled peptides rather attribute the d-spacing range between $1.3 \mathrm{~nm}$ and $1 \mathrm{~nm}$ to an interfibers periodic 
stacking. ${ }^{78-80}$ Our data do not allow us to have a clear-cut interpretation and further work, out of the present scope, will be needed to clarify this point.

From the data in Figure 1, we can safely argue that the gelling properties of sBola C16:0 SS derive from the spontaneous formation of a dense network of self-assembled fibers in water. Considering the frequency-independent profile of the viscoelastic moduli in Figure 2, characterized by an infinite relaxation time, which is classical in fiber-based gels, ${ }^{81}$ we can consider that the fiber are de facto "unbreakable", and in this case the elastic properties are driven by entanglements, in analogy to polymer gels. ${ }^{14}$ To confirm this assumption, we can follow the evolution of the elastic properties of the gel as a function of concentration, $G^{\prime}(C)$, in log-log scale (Figure 1c), in terms of the power law $G \propto A C^{n}$, well-known for colloidal and polymer gels: ${ }^{82-84}$ A is a constant and $n$ an empirical exponent, which characterizes the type of aggregation. Just after mixing, $t=0$ h, we can identify a $G^{\prime}(C)$ with an exponent close to 4 ( $n=3.9 \pm 1.1$, Figure $1 \mathrm{c}$ ), similar to those found in weakly aggregating polymer colloids, where it can vary between 3.7 and 4.5. ${ }^{83}$ After $15 \mathrm{~h}, \mathrm{G}^{\prime}(\mathrm{C})$ scales with a power law of $2.6 \pm 0.4$, a value which is close to what one finds in entangled polymer gels in a good solvent in a semidilute regime, and for which $G^{\prime}(C)$ on the plateau is expected to have $n=2.25$, as described by de Gennes. ${ }^{82} n$ values around 2 are found in both synthetic and biopolymer hydrogels, ${ }^{85-87}$ but also in fibrillary hydrogels, for instance composed of bacterial cellulose. ${ }^{88}$ The analogue $\mathrm{G}^{\prime}(\mathrm{C})$ behavior described by entanglements and observed both in polymer and fibrillary systems may seem surprising, but it is worth noting that self-assembled filaments can be described as polymers with a significant bending rigidity. ${ }^{89}$ To this regard, the theory developed by de Gennes on the dynamics of entangled polymer gels ${ }^{82}$ (the frequency range used to measure the mechanical properties must be higher than the disentanglement rate and lower than the characteristic frequency associated with the motion of the fiber between entanglement points) should be valid also in filamentous systems. This is observed experimentally in our and other systems. ${ }^{88}$

In summary, sBola C16:0 SS spontaneously self-assembles into weakly interacting colloidal fibrils at room temperature; the fibrils grow over time into fibers and their elastic properties are driven by entanglements, as observed for polymers. 


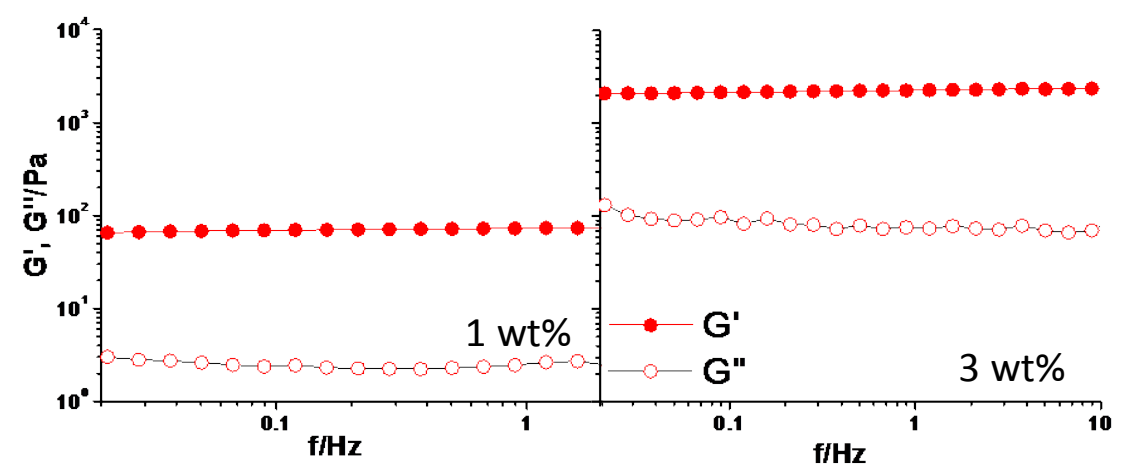

Figure 2 - Measurement of the storage and loss moduli for different sBola C16:0 SS concentration $(t=15 \mathrm{~h}$; $T=$ $25^{\circ} \mathrm{C}$ ) values as a function of the frequency. Experiments were carried out at at selected $\tau$ values so to be in the linear domain (0.2-1 Pa).

Time-dependent mechanical properties of the hydrogel.

The time-dependent evolution of the elastic properties of the hydrogel have been investigated in more detail by rheology, SANS and cryo-TEM. Figure S 2a shows the timedependent evolution of sBola C16:0 SS at $3 \mathrm{wt} \%$ at rest $(\mathrm{f}=0 \mathrm{~Hz})$ and at $\mathrm{f}=1 \mathrm{~Hz}$ over a period of $20 \mathrm{~h}$, without evaporation, showing no specific difference. The hydrogel displays a $\mathrm{G}^{\prime}$ value one order of magnitude higher than $\mathrm{G}^{\prime \prime}$, the loss modulus from $\mathrm{t}=0 \mathrm{~h}$ and until the end of the experiment, indicating an elastic behavior. The storage modulus $\mathrm{G}^{\prime}$ starts at about $200 \mathrm{~Pa}$ at $\mathrm{t}=0$ $\mathrm{h}$ and increases by a factor ten over $20 \mathrm{~h}$. Beyond $20 \mathrm{~h}$ and due to evaporation, the experiment could not be pursued any longer; however, although a plateau is not reached yet after $20 \mathrm{~h}$, the slope of $\mathrm{G}^{\prime}(\mathrm{t})$ in the range $15<\mathrm{t}(\mathrm{h})<20$ is 0.03 , a value about 16 times smaller than in the first hour of the experiment, thus indicating that the kinetics has considerably reduced and the gel can be de-facto considered to be close to equilibrium.

The time-dependency of the mechanical properties raises questions about the nano and mesoscale structure. SANS experiments are presented in Figure S $2 \mathrm{~b}$. Despite the truncated qrange probed with respect to SAXS (Figure 1d), all data are characterized by the same Bragg diffraction peak and scattering profile at low-q, thus indicating that the morphology of, and molecular packing within, the self-assembled fibers do not vary with time. The presence of fibers is also observed at very low concentration $(0.3 \mathrm{wt} \%)$ at $\mathrm{t}=0 \mathrm{~h}$ and after $12 \mathrm{~h}$, when the solution is fluidic at any time and no hydrogel is formed, as shown by the corresponding SANS data (Figure S 3), the shape of which is analogous to the system at higher concentration. Cryo-TEM data 
confirm these hypotheses: Figure S 4 shows that the sample at $3 \mathrm{wt} \%$ and $\mathrm{t}=0 \mathrm{~h}$ is significantly composed of self-assembled fibers displaying the same morphological features described for the sample at $1 \mathrm{wt} \%$ (Figure 1e and Figure $\mathrm{S} 5)$. After $\mathrm{t}=15 \mathrm{~h}(\mathrm{C}=1 \mathrm{wt} \%$, Figure $\mathrm{S}$ 6), when the hydrogel has the highest storage modulus (Figure 1c), cryo-TEM confirms that the mesoscale morphology does not vary while the length increases, confirming that both fiber growth and entanglement are responsible for the gel formation.

The high and low-magnification cryo-TEM images in Figure S 6 show that the sBola C16:0 SS SAFiN is constituted by a dense network of entangled bundles of fibers, most of which seem to be composed of twisted ribbons having a pitch of about $250 \mathrm{~nm}$ and a cross-section below 20 nm. LMWG fibers can nucleate and grow in at least three different ways, each one providing a SAFiN with different viscoelastic properties. When nucleation is homogeneous and fiber growth is "infinite", gel network is strong and characterized by transient entanglements, in analogy with polymers materials. ${ }^{82}$ Whenever growth prevail over nucleation, highly branched, spherulitic, networks are rather characterized by permanent junctions and the corresponding gel has overall poorer mechanical properties. ${ }^{24,90-92}$ Rheology and cryo-TEM data show that the hydrogel studied in this work has the structural features of a homogeneous gel network rather than a spherulitic one.

\section{Temperature-dependent properties of the hydrogel.}

Figure 3a shows the evolution of $\mathrm{G}^{\prime}$ and $\mathrm{G}^{\prime \prime}$ with temperature from $5^{\circ} \mathrm{C}$ to $35^{\circ} \mathrm{C}$ at fixed stress and frequency, where each temperature is reached after dispersion of the sample in water at $25^{\circ} \mathrm{C}$, at which fibers readily form, as discussed above (Figure 1 and Figure 2). The present study concerns a temperature evolution from $\mathrm{T}=25^{\circ} \mathrm{C}$ to $\mathrm{T}_{\mathrm{f}}$, where $5^{\circ} \mathrm{C}<\mathrm{T}_{\mathrm{f}}<35^{\circ} \mathrm{C}$. Three regions can be identified: 1$)$ at $\mathrm{T}<20^{\circ} \mathrm{C}$ the hydrogel is weak, characterized by $\mathrm{G}^{\prime} \sim 10^{2} \mathrm{~Pa}\left(\mathrm{G}^{\prime}\right.$ and $\mathrm{G}^{\prime \prime}$ at $\mathrm{T}=$ $5^{\circ} \mathrm{C}$ as a function of time are given in Figure S 7 and Figure $\mathrm{S} 2$ in the $20^{\circ} \mathrm{C}<\mathrm{T}<35^{\circ} \mathrm{C}$ region, the hydrogel is the stiffest, with $\mathrm{G}^{\prime} \sim 10^{3} \mathrm{~Pa} ; 3$ ) at $\mathrm{T}>35^{\circ} \mathrm{C}, \mathrm{G}^{\prime}$ abruptly drops down and cannot be properly measured: the sample becomes a solution. The strength of the gel is studied as a function of stress applied between $10^{\circ} \mathrm{C}$ and $30^{\circ} \mathrm{C}$. The short length of the viscoelastic linear plateau in the range of 0.8 $\mathrm{Pa}$ to 1.6 $\mathrm{Pa}$ shows that the gel formed is very fragile (Figure $3 \mathrm{~b}$ ).

These data can be explained by SANS in Figure 3c, which show a typical micellar scattering profile above $\mathrm{T}=40^{\circ} \mathrm{C}$ at any concentration, if compared to the discussed fiber-like scattering profile at $\mathrm{T}=25^{\circ} \mathrm{C}$. Similar SANS profiles of micellar aggregates have been described 
before for acidic sophorolipids. ${ }^{93,94}$ A standard Guinier analysis ${ }^{95,96}$ of the micellar scattering profile performed below $\mathrm{q}<1$ provides an average radius of gyration, $\mathrm{R}_{\mathrm{g}}=0.9 \pm 0.1 \mathrm{~nm}$ which, in the hypothesis of spherical objects, corresponds to a sphere of radius, $\mathrm{R}=1.2 \pm 0.1 \mathrm{~nm}$ (Figure $\mathrm{S}$ 8a). This is confirmed by the numerical modelling of the SANS curve (details concerning the modelling are provided on Page S9, in the Supporting Information) using a homogeneous sphere form factor, providing $\mathrm{R}=1.3 \pm 0.1 \mathrm{~nm}$ (Figure $\mathrm{S} 8 \mathrm{~b}$ ). This size could be compatible with a micelle constituted of interpenetrated sBola C16:0 SS, analogous to what we have observed before on a similar acidic sophorolipid, ${ }^{48}$ although one must assume a bent configuration of sBola C16:0 SS within the micelle, because its fully-stretched size $(>\sim 4 \mathrm{~nm})$ is longer than the micellar radius. Finally, a closer look at Figure 3c shows that the $10 \mathrm{wt} \%$ sample shows a noticeable Bragg diffraction peak, characteristic of the self-assembled fibers, and indicating that the micelle-fiber equilibrium is both temperature and concentration dependent.
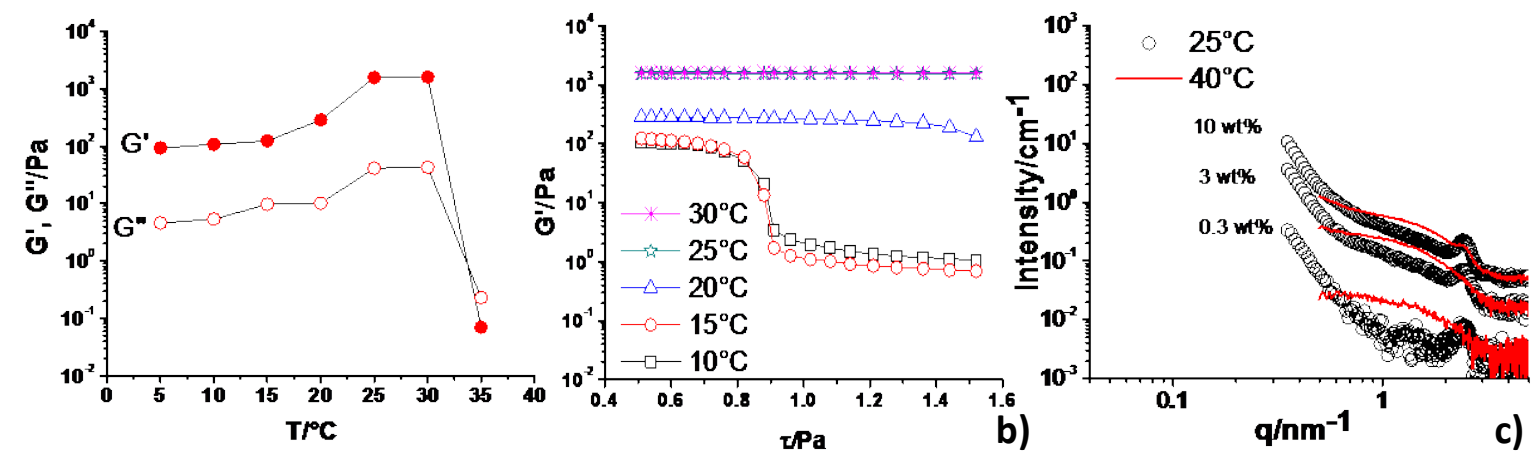

Figure 3 - Experiments performed on sBola C16:0 SS hydrogel at $t=15 \mathrm{~h}$ and $\mathrm{C}=3 \mathrm{wt} \%$. a) Evolution of the storage and loss moduli with temperature at $\mathrm{f}=1 \mathrm{~Hz}, \tau=0.5 \mathrm{~Pa}$. b) Evolution of the storage modulus as a function of the applied stress at fixed frequency $(f=1 \mathrm{~Hz})$ for temperature range between $10^{\circ} \mathrm{C}$ and $\left.30^{\circ} \mathrm{C} . \mathrm{c}\right) \mathrm{SANS}$ data recorded as a function of concentration and temperature $\left(\mathrm{T}=25^{\circ} \mathrm{C}\right.$ and $\left.\mathrm{T}=40^{\circ} \mathrm{C}\right)$.

To study the kinetic and thermodynamic parameters of the hydrogel formation, we study hereafter the sol-gel transition in the $40^{\circ} \mathrm{C}-5^{\circ} \mathrm{C}$ temperature interval. ${ }^{24,90,97}$ Figure 4 shows the time-dependency of the complex modulus $G^{*}$, obtained from the storage and loss moduli, $G^{\prime}$ and $\mathrm{G}^{\prime \prime}$ according to the standard relationships $\tan \delta=\frac{G^{\prime \prime}}{G^{\prime}}, G^{\prime}=G^{*} \cos \delta$ and $G^{\prime \prime}=G^{*} \sin \delta$; the values for $G^{\prime}$ and $G^{\prime \prime}$ are given in Figure S 9. Experiments have been run at $\mathrm{T}=25^{\circ} \mathrm{C}$ after cooling a sBola C16:0 SS solution (3 wt\%), initially set at $\mathrm{T}=35^{\circ} \mathrm{C}$ for 10 minutes. At the outset, $\mathrm{G}^{*}$ is very low, as the material is very fluid. In the interval between $30 \mathrm{~min}$ and $50 \mathrm{~min}, \mathrm{G}^{\prime}$ and $\mathrm{G}^{\prime \prime}$ 
become measurable; the gel time occurs when G' overtakes G" (Figure S 9), that is $42<\mathrm{tgel}_{\text {gel }} / \mathrm{min}$ $<60$, reported on Figure 4, while a plateau is reached already after $4 \mathrm{~h}$, with $\mathrm{G}^{\prime} \sim 4 \times 10^{3} \mathrm{~Pa}$. These data indicate that, if the exact value of $t_{\text {gel }}$ may fluctuate within a range of $15 \mathrm{~min}$ to $20 \mathrm{~min}$, the plateau value reached for the complex moduli are in all cases above $10^{3} \mathrm{~Pa}$. This value range indicates the formation of a stiff hydrogel with a comparable storage modulus obtained by direct dispersion of the sample in water at $25^{\circ} \mathrm{C}$ (rest $15 \mathrm{~h}$ ) (Figure 1c).

The heating-cooling cycle is robust, as shown by its reversibility presented in Figure 5a and Figure 5b: 20 temperature cycles have been carried out between $25^{\circ} \mathrm{C}$ and $35^{\circ} \mathrm{C}$, during a period of $24 \mathrm{~h}$. In order to combine a gel recovery providing satisfying mechanical properties with the highest number of cycles within $24 \mathrm{~h}$, so to exclude a water evaporation, a recovery time of 1 h was chosen. Under these conditions one finds $\mathrm{G}^{\prime}=995 \pm 577 \mathrm{~Pa}$, a value which shows that, despite its large variability due to the uncompleted recovery of the gel (which needs at least $4 \mathrm{~h}$, Figure 4), the sol-gel transition for sBola C16:0 SS is highly reproducible and robust.

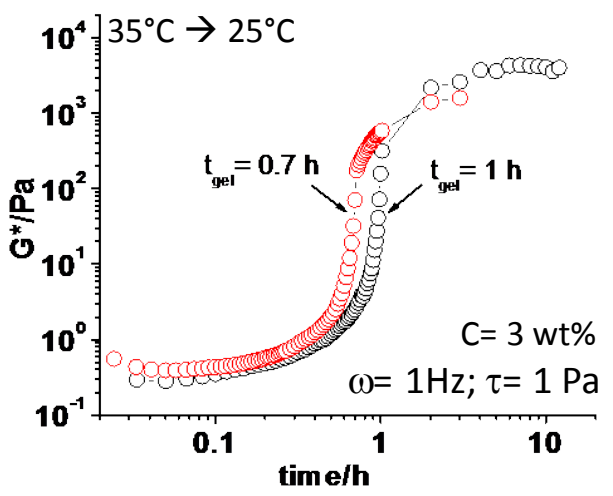

Figure 4 - Time-dependent evolution of the complex modulus, G* $(f=1 \mathrm{~Hz}, \tau=1 \mathrm{~Pa})$, recorded on a sBola C16:0

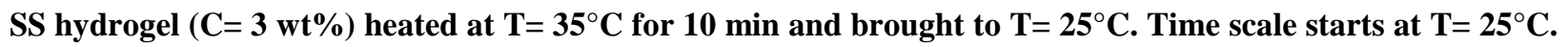
The red and black empty circles represent two different samples under the same experimental conditions. The corresponding $G^{\prime}$ and $G^{\prime \prime}$ are shown in Figure S 9. Values for tgel are reported for each curve and they are determined at the crossing between G' and G' (Figure S 9). Sampling was done as follows: 60 measurements/h up to $1 \mathrm{~h}$, then 1 measurement/h until the end of the experiment. 

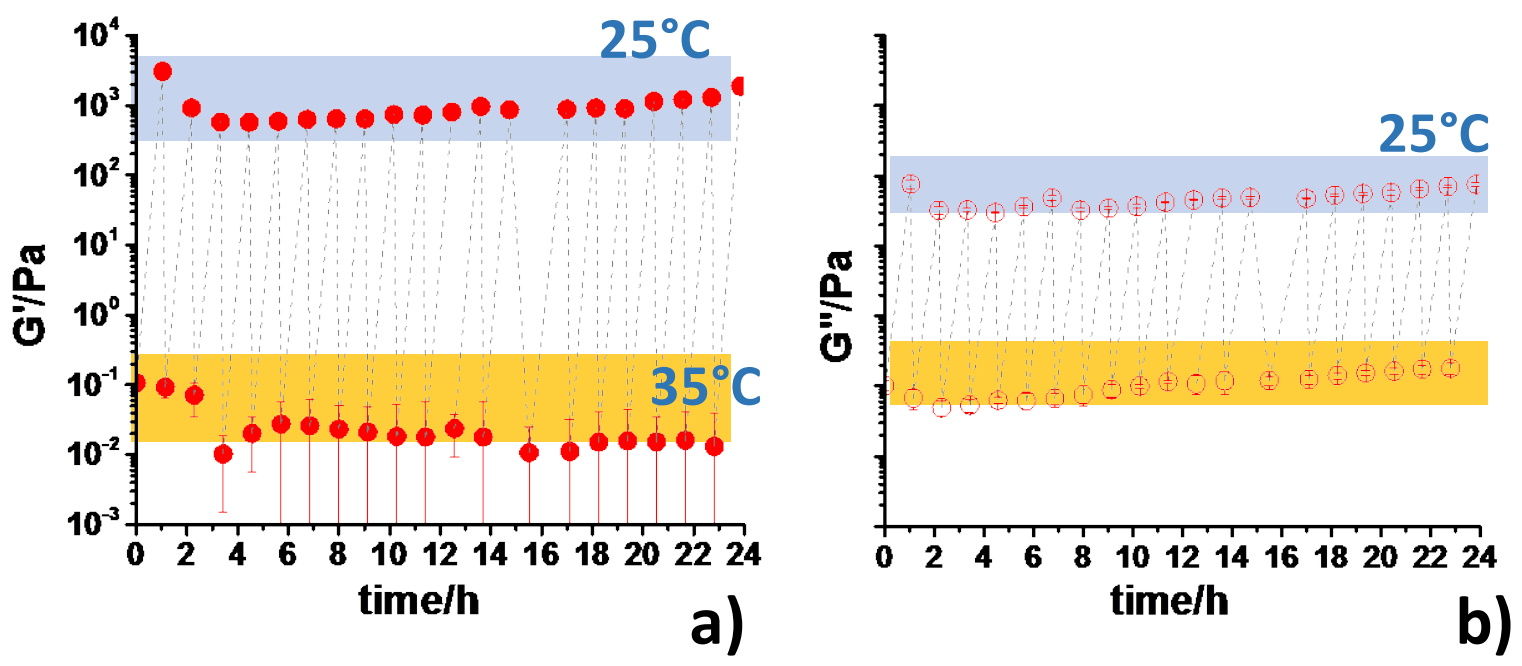

Figure 5 - Evolution of the storage (a) and loss (b) moduli over a temperature cycle $\left(25^{\circ} \mathrm{C} \rightarrow 35^{\circ} \mathrm{C}\right)_{20}$ during 24 h. $\mathrm{C}=3 \mathrm{wt} \%, \mathrm{f}=1 \mathrm{~Hz}$. The measurement were performed in the linear viscoelastic domain, varying as follows: $0.8<\tau(\mathrm{Pa})<1$ at $\mathrm{T}=25^{\circ} \mathrm{C}$ and $0.08<\tau(\mathrm{Pa})<0.10$ at $\mathrm{T}=35^{\circ} \mathrm{C}$.

Quantification of the fiber fraction.

Solution NMR probes mobile molecular species, of which the homonuclear interactions (dipolar coupling in particular) are averaged by Brownian motion. When the mobility is reduced due to a phase transition (e.g., liquid-to-solid), the transverse relaxation time becomes too short (inversely proportional to the peak width) to be detected by solution NMR and the slower species become de-facto "invisible" (the peaks become too broad). ${ }^{39,35,98,77,99}$ Under this assumption, one can assume that the normalized peak area is associated to the micellar fraction, $X_{M}$; as a consequence, we use NMR to monitor the fraction of fibers, $X_{F}=\left(1-X_{M}\right)$, in solution at all times, and in particular its evolution with time and temperature. ${ }^{100}$

With the intention of quantifying the sol-gel transition, and in particular the micelle-tofiber phase change, we have run a time and temperature-resolved combined ${ }^{1} \mathrm{H}$ NMR experiment, presented in Figure 6. When a sBola C16:0 SS water solution is heated above $25^{\circ} \mathrm{C}$, a liquid micellar phase forms; its typical ${ }^{1} \mathrm{H}$ NMR signal is shown in Figure 6 a at $\mathrm{T}=40^{\circ} \mathrm{C}$. The aliphatic signal is between 1.0 and $2.0 \mathrm{ppm}$, the sophorose signal is detected between 3.0 and $4.1 \mathrm{ppm}$ while the anomeric proton of sophorose is at $4.55 \mathrm{ppm}$. The sharp signal between 4.5 and $5.0 \mathrm{ppm}$ is attributed to water and a signal at $0.0 \mathrm{ppm}$ (not shown in the figure) belongs to TMSPd4, used as a reference throughout the experiment and contained in an independent coaxial insert, to avoid 
mixing with the sample. In the micellar phase at $\mathrm{T}=40^{\circ} \mathrm{C}$, the spectrum is characterized by wellresolved peaks, which reflect the typical fingerprint of a fast-tumbling molecular motion, as expected in a micellar environment in water.
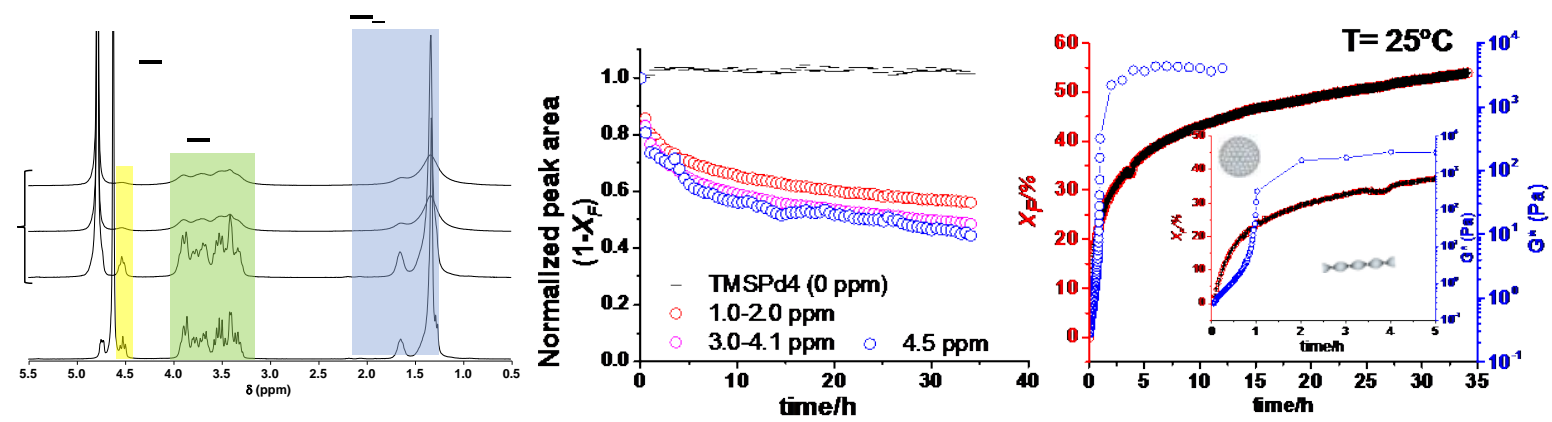

Figure 6 - a) ${ }^{1} \mathrm{H}$ solution NMR spectra of the sBola C16:0 SS (C=3 wt \%) sol-gel transition in $\mathrm{D}_{2} \mathrm{O}$. The sample is equilibritated at $\mathrm{T}=40^{\circ} \mathrm{C}$ in the NMR tube outside the probe and then inserted in the probe set at $\mathrm{T}=40^{\circ} \mathrm{C}$. After recording the first spectrum, the probe temperature is lowered in-situ at $\mathrm{T}=25^{\circ} \mathrm{C}$. The time $\mathrm{t}=\mathbf{0 ~ h}$ starts at $\mathrm{T}=25^{\circ} \mathrm{C}$. b) Time evolution of the ${ }^{1} \mathrm{H}$ NMR normalized peak area values sampled every $30 \mathrm{~min}$ and measured for the chemical shift values given on the decays profiles. The black hyphens refer to TMPSd4 dissolved in $D_{2} O$ inside an insert coaxial tube, used as an external control both for chemical shift and peak area.

When the temperature is cooled instantly from $\mathrm{T}=40^{\circ} \mathrm{C}$ to $\mathrm{T}=25^{\circ} \mathrm{C}$ inside the NMR coil, the first spectrum is recorded as $\mathrm{t}=0 \mathrm{~h}$ at $\mathrm{T}=25^{\circ} \mathrm{C}$, then each spectrum is recorded every $30 \mathrm{~min}$ over 34 hours (please note that in this case evaporation is limited and contained because the NMR tube is closed). When looking at the first spectrum at $\mathrm{t}=0 \mathrm{~h}$, one can already observe a slight broadening of the linewidth if compared to the spectrum at $\mathrm{T}=40^{\circ} \mathrm{C}$; at longer times, $\mathrm{t}=10 \mathrm{~h}$ and $20 \mathrm{~h}$, all signals have lost their initial resolution and they have massively broadened, indicating the ongoing micelle-to-fiber phase transition. It is crucial to note that the signal is always attributed to sBola C16:0 SS in a micellar environment; the mobility is reduced more and more by the presence of the fibrillary phase, which could only be characterized directly by solid-state NMR. ${ }^{55,101}$ Under these circumstances, we follow the decay of the integrated signals of sBola C16:0 SS in their micellar phase over time (Figure 6b) and quantify the extent of the micelle-to-fiber phase transition. 
From Figure $6 \mathrm{~b}$ we conclude that all signals have the same decay profile, which indicates that the entire sBola C16:0 SS molecule is involved in the phase transition; the signal of TMSPd4, which has no time-dependent evolution, is also shown as a control. If one associates the normalized peak area to $X_{M}$, the fraction of molecules in a micellar environment, one can then easily say that $X_{F}=\left(1-X_{M}\right)$ corresponds to the fraction of molecules in the fiber phase. By associating $X_{F}$ measured by NMR to the viscoelastic properties measured by rheology under analogous conditions, one can determine: 1) the minimal fraction of sBola C16:0 SS in the fiber phase that are needed to form a gel and 2) the total fraction of molecules in the fiber phase when the gel can be considered to be at equilibrium. These data are shown in Figure 6c, where the G*(t) profile (black empty circles in Figure 4 ) having a $t_{\text {gel }}=1 \mathrm{~h}$ has been selected to represent the viscoelastic behavior of the sample.

Figure 6c shows that only 20\% of sBola C16:0 SS is in the fiber form at $t_{\text {gel }}$ and not more than $40 \%$ when $\mathrm{G}^{*}$ enters the plateau. In fact, even after $35 \mathrm{~h}$, the molecular population in the fiber phase does not exceed 60\%, thus showing that the micelle-to-fiber phase transition is not quantitative, although this is enough to obtain a stiff hydrogel $\left(\mathrm{G}^{\prime} \sim 4 \times 10^{3} \mathrm{~Pa}\right)$. Since the $\mathrm{G}^{*}$ plateau is reached after about $4 \mathrm{~h}$, one can suppose that the 10\% increase in the NMR signal between $5 \mathrm{~h}$ and $35 \mathrm{~h}$ can be explained by fiber growth, although with a limited impact on the rheological properties.

Mechanism of fiber formation at $T=25^{\circ} \mathrm{C}$.

The sol-gel transition between $40^{\circ} \mathrm{C}$ and $5^{\circ} \mathrm{C}$ has been used to quantify further the micelleto-fiber transition. Determination of the sol-gel transition temperature, $\mathrm{T}_{\mathrm{g}}$, and the minimum gel concentration, $\mathrm{C}_{\text {gel }}$, at $\mathrm{T}=25^{\circ} \mathrm{C}$ are determined in Figure $\mathrm{S} 10 \mathrm{a}$ and Figure $8 \mathrm{~b}$ by mean of both ${ }^{1} \mathrm{H}$ solution NMR. Evolution of the FWHM and normalized peak area signals recorded on the alkyl resonance at $1.3 \mathrm{ppm}$ of sBola C16:0 SS indicate a break in their temperature-dependent evolution between $28^{\circ} \mathrm{C}$ and $29^{\circ} \mathrm{C}$ (Figure S 10a). A $\mathrm{T}_{\mathrm{g}}=28.3 \pm 0.2^{\circ} \mathrm{C}$ is estimated, although the nucleation and growth probably start at higher temperature, in the vicinity of $35^{\circ} \mathrm{C}$, where the peak area starts to decrease while the FWHM starts to increase. These data are in very good agreement with the estimation of $\mathrm{T}_{\text {gel }}$ by rheological measurements. Figure S 10c and Figure S 10d presents the timedependent evolution of $G^{\prime}$ and $G^{\prime \prime}$ across the gel-to-sol and sol-gel transition, respectively. One can measure an average value of $\mathrm{T}_{\text {gel }}=28.1 \pm 1.0^{\circ} \mathrm{C}$, where the larger error depends on the different 
methodology used to estimate $\mathrm{T}_{\text {gel }}$ (please, refer to Figure $\mathrm{S} \mathrm{10c,d).} \mathrm{It} \mathrm{is} \mathrm{worth} \mathrm{noting} \mathrm{that} \mathrm{in} \mathrm{the}$ gel-to-sol transition, the estimated $T_{\text {gel }}$ corresponds to the inflection point where $G^{\prime}$ decreases, whereas $\mathrm{G}^{\prime \prime}>\mathrm{G}^{\prime}$ at $\mathrm{T}=32.5^{\circ} \mathrm{C}$. The combined set of NMR and rheology data show that in the solgel transition, nucleation probably starts above $30^{\circ} \mathrm{C}$, while growth starts in the vicinity of $28^{\circ} \mathrm{C}$. On the contrary, in the gel-to-sol transition, the fibers start to break in the vicinity of $28^{\circ} \mathrm{C}$, while above $30^{\circ} \mathrm{C}$ the system loses its gel behavior. Finally, one can estimate $\mathrm{C}_{\text {gel }}$ as a function of concentration using NMR: the narrow values of the FWHM indicate a sol phase. The evolution of the FWHM with concentration at $\mathrm{T}=25^{\circ} \mathrm{C}$ (Figure S 10b) identifies a $\mathrm{C}_{\text {gel }}=0.25 \pm 0.04 \mathrm{wt} \%$.

The Avrami equation is commonly used to determine the nucleation and growth mechanism of bulk crystals ${ }^{102,103}$ and it has been successfully applied to the study of SAFiN nucleation and growth in LMWG systems both in water and organic solvents. ${ }^{24,90,97}$ The general form of the Avrami equation is $X_{c r}=1-e^{-k t^{n}}, X_{c r}$ is the volume fraction of the crystalline phase at a given time of the reaction, $k$ is the kinetic constant, $t$ is the time and $n$ is the type of nucleation (heterogeneous or instantaneous) and dimensionality of crystal growth, and where $n$ is commonly contained between 1 and 4, indicating a 1-D or fiber-like, 2-D or platelet-like and 3-D growth. Finally, the Avrami plot is generally applied in the nucleation and growth phase, so to avoid complex crystallization effects. ${ }^{104}$ Plotting $\ln \left\{-\ln \left[\left(1-X_{F}\right)\right]\right\}$ against $\ln (\mathrm{t})$ gives access to $n$ (slope) and $\ln (\mathrm{k})$ (intercept).

Figure S 11b and Figure S 11c show the Avrami plots obtained from NMR and rheology data at $\mathrm{T}=25^{\circ} \mathrm{C}$ respectively, and where $X_{c r} \equiv X_{F}=\left(1-X_{M}\right)=\left(1-\mathrm{A}_{1.3}\right),{ }^{100}$ where $\mathrm{A}_{1.3}$ is the normalized peak area at $\delta=1.3 \mathrm{ppm}$ for NMR experiments (Figure 6b), while $X_{c r} \equiv$ $X_{F(\text { rheo })} \frac{G^{*}(t)-G_{0}^{*}}{G^{*}(\max )-G_{0}^{*}}$, for rheology experiments (Figure 4). ${ }^{24,29}$ In the latter, $G^{*}(t)$ and $G^{*}(\max )$ are taken as average values, ${ }^{29}$ respectively at $\mathrm{t}=0$ and on the plateau, and time can be safely replaced by ( $\left.t-t_{g e l}\right)$, because the Avrami plot is used to describe mainly the nucleation and growth phase, that is when gelling occurs. ${ }^{24,90}$ The value of $n$ that we found by NMR is systematically below 1 , where one can even observe a two-slope behavior (Figure S $11 \mathrm{~b}$ ), with $n=0.8$ and $n=0.3$. The Avrami plot obtained from rheology experiments confirm values of $n$ below $1(n=0.6)$. Although unexpected, values of $n$ below unity and multiple slope behavior of the Avrami plot are far from being uncommon: typical interpretation has been attributed to a diffusion-controlled crystallization 
growth and heterogenous nucleation, where shorter times $(\ln (\mathrm{t})<8)$ are characterized by nucleation and longer times $(\ln (t)>8)$ by growth. ${ }^{29,97,104,105}$

\section{Control of hydrogel elastic properties at $T=5^{\circ} \mathrm{C}$}

The mechanical properties of SAFIN are known to depend on the temperature variation, which controls fiber growth through modulation of the supersaturation..$^{92}$ This is observed in the system studied in this work. When the temperature is lowered from $25^{\circ} \mathrm{C}$ to $5^{\circ} \mathrm{C}$, the elastic modulus of the hydrogel is smaller (Figure S 2), and several hypotheses can be formulated. The elastic properties of self-assembled fibrillary systems displaying a Maxwellian behavior was shown to improve at lower temperatures $;{ }^{14}$ obviously, this is not the case here, and one can reasonably account for the existence of a gel-to-sol transition temperature below room temperature, as discussed for other systems. ${ }^{106,107}$ However, this hypothesis has to be excluded because the system has the classical visual appearance of a gel at temperatures as low as $5^{\circ} \mathrm{C}$. The FWHM with time from $\mathrm{T}_{\text {sol }}\left(40^{\circ} \mathrm{C}\right)$ to $\mathrm{T}_{\text {gel }}\left(5^{\circ} \mathrm{C}\right.$ and $15^{\circ} \mathrm{C}$, Figure $\left.\mathrm{S} 11 \mathrm{a}\right)$ shifts from about $10 \mathrm{~Hz}$ at $40^{\circ} \mathrm{C}$ to $35 \mathrm{~Hz}$ at $5^{\circ} \mathrm{C}$, which is also typical sign of gel formation. Interestingly, the FWHM at $25^{\circ} \mathrm{C}$ at equilibrium $(50 \mathrm{~Hz})$ is larger than at $5^{\circ} \mathrm{C}$, a fact which is in agreement with the better mechanical properties of the hydrogel prepared at $25^{\circ} \mathrm{C}$; nonetheless, the kinetics of gel formation is faster for strong undercooling. At low undercooling, $\Delta \mathrm{T}\left(\mathrm{T}_{\text {gel }}-\mathrm{T}_{\text {sol }}\right)=-15^{\circ} \mathrm{C}, 1.5 \mathrm{~h}$ are necessary to achieve a FWHM of $25 \mathrm{~Hz}$, while this value is reached after only few minutes for strong undercooling $\left(\Delta \mathrm{T}=-35^{\circ} \mathrm{C}\right)$.

The second hypothesis for a weaker hydrogel at $5^{\circ} \mathrm{C}$ can be formulated in terms of structural arguments as a function of the undercooling protocol, which is known to be a crucial parameter in the formation of SAFiN. Under strong undercooling $\left(\Delta \mathrm{T}=-35^{\circ} \mathrm{C}\right)$ conditions, homogeneous nucleation and limited growth dominate the crystallization process, thus resulting in the significant formation of short-sized sBola C16:0 SS fibers. This is confirmed by the value of $X_{F}$ close to unity at $\mathrm{T}=5^{\circ} \mathrm{C}$ (Figure $\mathrm{S} 12 \mathrm{a}$ ): almost the entire micellar population transforms into fibers in few minutes. The corresponding $G^{\prime}, G^{\prime \prime}(f)$ for a sample undergoing strong undercooling is shown in Figure 7 (squares): $\mathrm{G}^{\prime}$ does not exceed few hundred Pascal. This is higher than what was found in Figure 3a (transition from pre-formed fibers at $25^{\circ} \mathrm{C}$ to $5^{\circ} \mathrm{C}$ ), but the order of magnitude is the same. Interestingly, upon gradual heating to $25^{\circ} \mathrm{C}$ (Figure S 12a), the fiber-tomicelles phase transition partially takes place and the final proportion of fibers lies in the vicinity 
of 0.6, as previously found. The corresponding FWHM for this set of experiments is evaluated to be between $27 \mathrm{~Hz}$ and $30 \mathrm{~Hz}$, for any temperature explored (Figure S 12c).

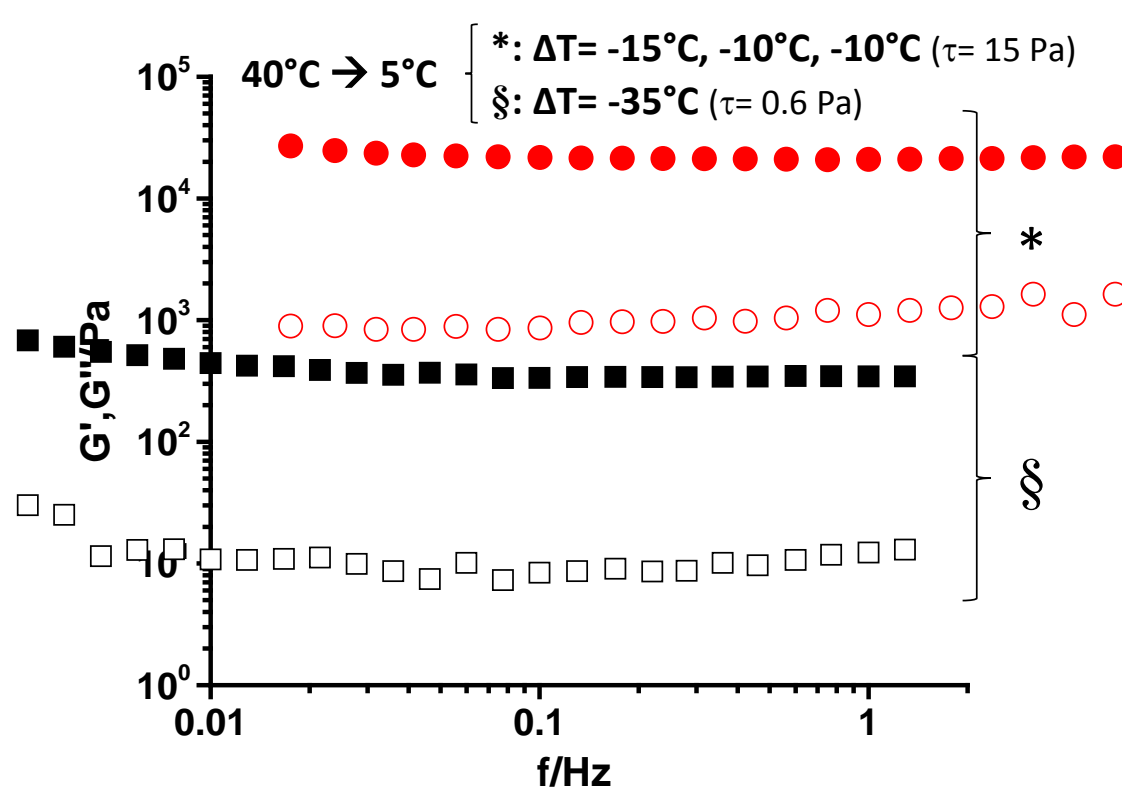

Figure 7 - Frequency-dependence of the elastic $G^{\prime}$ and loss $G^{\prime \prime}$ moduli of sBola $\mathrm{C16:0}$ SS hydrogel at $T=5^{\circ} \mathrm{C}$. This temperature is achieved by a large $\left(\Delta \mathrm{T}<-35^{\circ} \mathrm{C}\right.$, squares $)$ and low $\left(\Delta \mathrm{T}=-15^{\circ} \mathrm{C},-10^{\circ} \mathrm{C},-10^{\circ} \mathrm{C}\right.$, circles $)$ undercooling. Starting temperature is $\mathrm{T}=40^{\circ} \mathrm{C}$. All data are recorded in the linear domain regime.

Given the impact of the undercooling protocol, we have run another experiment in which the system is cooled down from $40^{\circ} \mathrm{C}$ to $5^{\circ} \mathrm{C}$, but with low undercooling $\left(15^{\circ} \mathrm{C}<\Delta \mathrm{T}<10^{\circ} \mathrm{C}\right)$. From the NMR data in Figure S $12 \mathrm{~b}$ and Figure S $12 \mathrm{~d}$ one finds that $X_{F}$ at $25^{\circ} \mathrm{C}$ and $5^{\circ} \mathrm{C}$ are respectively of $60 \%$ and $90 \%$, that is comparable to $X_{F}$ obtained with strong undercooling (Figure $\mathrm{S} 12 \mathrm{a})$. However, the values of the FWHM is higher, and it reaches $30 \mathrm{~Hz}$ at $25^{\circ} \mathrm{C}$ and $37 \mathrm{~Hz}$ at $5^{\circ} \mathrm{C}$. Under these conditions, the corresponding G'(f) (Figure 7, circles) increases by a factor 100 and it reaches $20 \mathrm{kPa}$, confirming the NMR data. The activation energy during the cooling cycle at small $\Delta \mathrm{T}$ is evaluated at $\mathrm{E}_{\mathrm{a}}=87.2 \pm 8.0 \mathrm{kJmol}^{-1}$ (Figure $\mathrm{S} \mathrm{13}$ ), which is in agreement with the activation energy values for the micelle-to-fiber phase transition classically measured in SAFiN, ${ }^{108,109}$ between $80 \mathrm{kJmol}^{-1}$ and $100 \mathrm{kJmol}^{-1}$. These experiments show that both temperature and kinetics of the micelle-to-fiber phase transition are able to control the elastic modulus of sBola C16:0 SS hydrogel and values above $10 \mathrm{kPa}$ at $3 \mathrm{wt} \%$ can be obtained. 
Table 1 - Summary of the major structural and mechanical parameters for the sBola C16:0 SS hydrogel obtained after dispersion in water at $\mathrm{T}=25^{\circ} \mathrm{C}$. $\mathrm{C}$ is concentration, $\mathrm{LF}_{\mathrm{F}}$ is the fiber length (median of log-normal distribution), $G_{\text {max }}^{\prime}$ is the value of elastic modulus $G^{\prime}$ at equilibrium.

\begin{tabular}{|c|c|c|c|c|}
\hline $\mathbf{C} / \mathbf{w t} \%$ & time/h & $\mathbf{L F}_{\mathbf{F}} / \mathbf{n m}$ & $\boldsymbol{G}_{\boldsymbol{m a x}}^{\prime} \mathbf{k P a}$ & Technique \\
\hline 3 & 15 & - & 2 & Rheology \\
10 & & & 44 & \\
\hline 1 & 0 & $436.6 \pm 30.8$ & - & Cryo-TEM \\
\hline
\end{tabular}

The entire set of data collected so far, which are summarized in Table 1 and Table 2 and represented in Figure 8, indicate that the magnitude of gelation is temperature-dependent but not process-dependent, because $X_{F}$ is practically the same at any temperature, independently of $\Delta \mathrm{T}$ and heating/cooling cycles as shown in Figure S 12. Nonetheless, both NMR and rheology show that the strength of the hydrogel increases when the sol-gel transition is approached with short and gradual undercooling: low undercooling favours an heterogeneous nucleation and a diffusioncontrolled mechanism, which promotes an infinite 1D fiber growth, as classically found in fibrillary gels. ${ }^{81}$

Table 2 - Summary of the major structural, mechanic and thermodynamic parameters for the sBola C16:0 SS hydrogel $(\mathrm{C}=3 \mathrm{wt} \%)$ obtained after a sol-gel transition (starting temperature is $40^{\circ} \mathrm{C}$ ). $\mathrm{T}$ is temperature, $\mathrm{C}$ is concentration, $t$ is time. $T_{\text {gel }}$ is the hydrogel-forming temperature at $G^{\prime}, G^{\prime \prime}$ crossover, $\Delta T$ is the undercooling defined as $\left(T_{\text {gel }}-T_{\text {sol }}\right), C_{\text {gel }}$ is the hydrogel-forming concentration, $t_{\text {gel }}$ is hydrogel-forming time, $n$ is the Avrami exponent, $X_{F}$ is the fraction of the compound in the fiber phase, $E_{a}$ is the activation energy, $G_{m a x}^{\prime}$ is the value of elastic modulus $G^{\prime}$ at equilibrium.

\begin{tabular}{|c|c|c|c|c|}
\hline \multicolumn{2}{|c|}{ Sol-gel transition } & $\mathbf{T} /{ }^{\circ} \mathbf{C}$ & $\Delta \mathbf{T} /{ }^{\circ} \mathbf{C}$ & Technique \\
\hline $\mathrm{T}_{\text {gel }} /{ }^{\circ} \mathrm{C}$ & $28.3 \pm 0.2$ & - & - & NMR \\
\hline $\mathrm{T}_{\text {gel }} /{ }^{\circ} \mathrm{C}$ & $28.1 \pm 1.0$ & - & - & Rheology \\
\hline $\mathrm{C}_{\text {gel }} / \mathrm{wt} \%$ & $0.25 \pm 0.04$ & 25 & - & NMR \\
\hline $\mathrm{t}_{\text {gel }} / \mathrm{h}$ & $0.85 \pm 0.15$ & 25 & -15 & Rheology \\
\hline$n$ & $0.3 \pm 4.10^{-4}$ & 25 & -15 & $\begin{array}{c}\text { NMR } \\
\text { Rheology }\end{array}$ \\
\hline$X_{F}$ & $6.6 \pm 0.1$ & 25 & -15 & NMR \\
\hline
\end{tabular}




\begin{tabular}{|c|c|c|c|c|}
\hline & $90 \%$ & 5 & -35 & \\
\hline $\mathrm{E}_{\mathrm{a}} / \mathrm{kJ} . \mathrm{mol}^{-1}$ & $87.2 \pm 8.0$ & - & - & NMR \\
\hline$G_{\text {max }}^{\prime} / \mathrm{kPa}$ & $4.0 \pm 0.3$ & 25 & -15 & Rheology \\
\hline$G_{\text {max }}^{\prime} / \mathrm{kPa}$ & 20 & 5 & $-15,-10,-10$ & Rheology \\
\hline
\end{tabular}

Under strong undercooling $\left(\Delta \mathrm{T}>-30^{\circ} \mathrm{C}\right)$, massive fibrillation occurs but growth in time is either limited, thus justifying the poor mechanical properties ${ }^{20}$ or, as commonly found for SAFiN, a higher degree of branching is developed. The branching distance is generally inversely proportional to the extent of undercooling: the higher $\Delta \mathrm{T}$, the smaller the branching distance, so the network is less homogeneous and contains more fractal spherulites, and branched gels signature can be obtained. A common feature in this case is the smaller value of the Avrami coefficient $n$, which is also found to be smaller in this system at $5^{\circ} \mathrm{C}(n<0.1$, estimated from the time evolution of $X_{F}$ at $\mathrm{T}=5^{\circ} \mathrm{C}$ and measured by ${ }^{1} \mathrm{H}$ NMR, data not shown) than at $25^{\circ} \mathrm{C}(n=0.3$, Figure S 11b). ${ }^{24,92}$ Branched gels are known to have lower elastic moduli with respect to homogeneous entangled fibrillar gels, ${ }^{25,91}$ a fact which can explain the worst elastic properties of sBola C16:0 SS hydrogels at $5^{\circ} \mathrm{C}$ under strong undercooling. On the contrary, low temperature combined with gentle cooling and small gradual undercooling provide a large extent of fibrillation with minimized branching, leading to higher homogeneity, thus favouring the formation of stronger gels. 


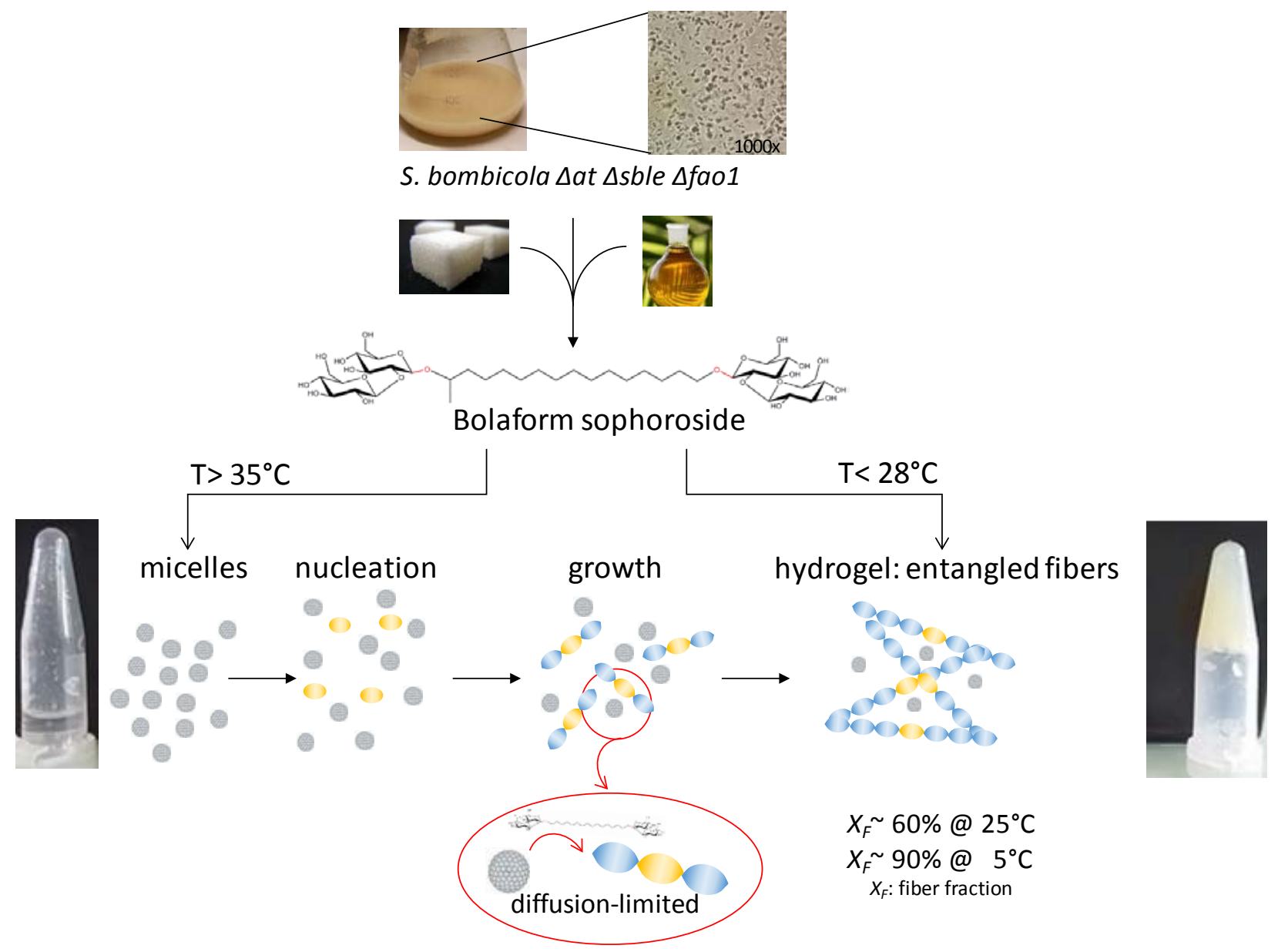

Figure 8 - Schematic summary of the sol-gel transition in water of the microbial sBola C16:0 SS glycobolaamphiphile. Temperature controls the volume fraction of the fibers $\left(90 \%\right.$ at $\left.5^{\circ} \mathrm{C}\right)$, while undercooling controls the elastic modulus ( $\mathrm{G}^{\prime}>10 \mathrm{kPa}$ for small gradual undercooling).

\section{Conclusion}

In this work we study the hydrogel-forming properties of a new biobased bolaform biosurfactant produced from a modified strain of $S$. bombicola. When the compound is dispersed in water below $28^{\circ} \mathrm{C}$, it self-assembles into twisted fibers having a diameter below $20 \mathrm{~nm}$ and length in the order of magnitude of $100 \mathrm{~nm}$. The fiber length increases with time, which induces entanglement and consequential increase of the viscosity. At equilibrium, the elastic modulus as a function of concentration scales as a power law with an exponent of 2.4, which is very close to the predicted value of 2.25 found in entangled polymers gels by de Gennes. ${ }^{82}$ Under these conditions, these materials exhibit elastic modulus in the order of the $\mathrm{kPa}$. 
The system is found to have a gel-transition temperature of $28^{\circ} \mathrm{C}$ and a minimal gel concentration of $0.25 \mathrm{wt} \%$. Above the $\mathrm{T}_{\text {gel, }}$, micelles are formed. Below $\mathrm{T}_{\text {gel, }}$, the fiber phase is stable, although both phases coexist in the order of $60: 40$ fibers:micelles at $25^{\circ} \mathrm{C}$, while at $5^{\circ} \mathrm{C}$ $90 \%$ of the compound assembles into fibers. The elastic modulus of the hydrogel can be controlled by the undercooling protocol between the gel and sol phase. At strong undercooling $\left(-35^{\circ} \mathrm{C}\right)$, the hydrogel is much weaker than for small, gradual, undercooling of about $10^{\circ} \mathrm{C} / 15^{\circ} \mathrm{C}$, where $\mathrm{G}^{\prime}$ can reach $20 \mathrm{kPa}$ at $5^{\circ} \mathrm{C}$. The thermodynamic and kinetics analysis show that the fibers undergo a diffusion-limited growth during the sol-gel transition with an activation energy below $100 \mathrm{~kJ}^{\mathrm{mol}}{ }^{-}$ 1, as expected for low molecular weight gelators.

This works shows that a new structural variation of the well-known sophorolipid biosurfactant spontaneously forms a hydrogel in water in the $5^{\circ} \mathrm{C}-28^{\circ} \mathrm{C}$ temperature range and with tuned elastic modulus between $100 \mathrm{~Pa}$ and $20 \mathrm{kPa}$. These properties have never been reported neither for sophorolipids nor for any other biobased glyco-amphiphile. This research should open the perspectives of employing this new class of biobased amphiphiles in a broad field of applications going from cosmetics to tissue engineering.

\section{Acknowledgements}

This work received financial support from the Institut Laue-Langevin (ILL), Grenoble, France, under the experiment number 9-12-481, and by the European Synchrotron Radiation Facility (ESRF), Grenoble, France, under the experiment number MX1821. This work benefited from the use of the SasView application, originally developed under NSF award DMR-0520547. SasView contains code developed with funding from the European Union's Horizon 2020 research and innovation programme under the SINE2020 project, grant agreement No 654000. Dr. François Ribot (LCMCP) is kindly acknowledged for his assistance on the NMR experiments. Finally, also financial support was received from European Horizon 2020 Bio-Based Industries (BBI) Consortium Project Carbosurf (grant number 669003).

\section{References:}

1 P. J. Flory, Faraday Discuss. Chem. Soc., 1974, 57, 7.

$2 \quad$ K. Y. Lee and D. J. Mooney, Am. Chem. Soc., 2001, 101, 203-225.

3 A. N. Moore and J. D. Hartgerink, Acc. Chem. Res., 2017, 50, 714-722.

$4 \quad$ K. Y. Lee and D. J. Mooney, Chem. Rev., 2001, 101, 203-225. 
J. Zhu and R. E. Marchant, Expert Rev. Med. Devices, 2011, 8, 607-626.

6 B. F. Lin, K. A. Megley, N. Viswanathan, D. V Krogstad, L. B. Drews, M. J. Kade, Y. Qian and M. V Tirrell, J. Mater. Chem., 2012, 22, 19447-19454.

$7 \quad$ C. Alexander, Nat. Mater., 2008, 7, 767-768.

8 K. H. Bae, L.-S. Wang and M. Kurisawa, J. Mater. Chem. B, 2013, 1, 5371.

$9 \quad$ P. Baglioni, E. Carretti and D. Chelazzi, Nat. Nanotechnol., 2015, 10, 287-290.

10 D. Díaz Díaz, D. Kühbeck and R. J. Koopmans, Chem. Soc. Rev., 2011, 40, 427-448.

11 C. Keplinger, J.-Y. Sun, C. C. Foo, P. Rothemund, G. M. Whitesides and Z. Suo, Science (80-. )., 2013, 341, 984-987.

12 R. G. Weiss, J. Am. Chem. Soc., 2014, 136, 7519-7530.

13 L. a Estroff and A. D. Hamilton, Chem. Rev., 2004, 104, 1201-1218.

14 S. R. Raghavan and J. F. Douglas, Soft Matter, 2012, 8, 8539.

15 L. E. Buerkle and S. J. Rowan, Chem. Soc. Rev., 2012, 41, 6089.

16 K. Basu, A. Baral, S. Basak, A. Dehsorkhi, J. Nanda, D. Bhunia, S. Ghosh, V. Castelletto, I. W. Hamley and A. Banerjee, Chem. Commun., 2016, 52, 5045-5048.

17 S. Basak, N. Nandi, S. Paul, I. W. Hamley and A. Banerjee, Chem. Commun., 2017, 53, 5910-5913.

18 A. Baral, S. Roy, S. Ghosh, D. Hermida-Merino, I. W. Hamley and A. Banerjee, Langmuir, 2016, 32, 1836-1845.

19 J. Raeburn, A. Zamith Cardoso and D. J. Adams, Chem. Soc. Rev., 2013, 42, 5143-5156.

20 F. M. Menger and K. L. Caran, J. Am. Chem. Soc., 2000, 122, 11679-11691.

21 H. Komatsu, M. Ikeda and I. Hamachi, Chem. Lett., 2011, 40, 198-200.

22 C. Yan and D. J. Pochan, Chem. Soc. Rev., 2010, 39, 3528.

23 M. Lescanne, A. Colin, O. Mondain-Monval, F. Fages and J. L. Pozzo, Langmuir, 2003, 19, 2013-2020.

24 X. Y. Liu and P. D. Sawant, Adv. Mater., 2002, 14, 421-426.

25 R. Y. Wang, X. Y. Liu, J. Narayanan, J. Y. Xiong and J. L. Li, J. Phys. Chem. B, 2006, 110, 25797-25802.

26 R. Wang, X.-Y. Liu, J. Xiong and J. Li, J. Phys. Chem. B., 2006, 110, 7275.

27 X. Y. Liu, Top. Curr. Chem., 2005, 256, 1-37.

28 W. K. Burton, N. Cabrera and F. C. Frank, Philos. Trans. R. Soc. A Math. Phys. Eng. Sci., 1951, 243, 299-358.

29 X. Huang, P. Terech, S. R. Raghavan and R. G. Weiss, J. Am. Chem. Soc., 2005, 127, 4336-4344.

30 X. Y. Liu, P. D. Sawant, W. B. Tan, I. B. M. Noor, C. Pramesti and B. H. Chen, J. Am. Chem. Soc., 2002, 124, 15055-15063.

31 M. Lescanne, P. Grondin, A. d’Aléo, F. Fages, J.-L. Pozzo, O. M. Monval, P. Reinheimer and A. Colin, Langmuir, 2004, 20, 3032-3041.

32 M. J. Clemente, J. Fitremann, M. Mauzac, J. L. Serrano and L. Oriol, Langmuir, 2011, 27, $15236-15247$.

33 J. Clemente, P. Romero, J. L. Serrano, J. Fitremann and L. Oriol, 2012.

34 S. Bhattacharya and S. N. G. Acharya, Chem. Mater., 1999, 11, 3504-3511.

35 J. H. Fuhrhop, S. Svenson, C. Boettcher, E. Rössler and H. M. Vieth, J. Am. Chem. Soc., 1990, 112, 4307-4312.

36 J. H. Jung, J. A. Rim, W. S. Han, S. J. Lee, Y. J. Lee, E. J. Cho, J. S. Kim, Q. Ji and T. Shimizu, Org. Biomol. Chem., 2006, 4, 2033-8. 
I. Nakazawa, M. Masuda, Y. Okada, T. Hanada, K. Yase, M. Asai and T. Shimizu, Langmuir, 1999, 15, 4757-4764.

38 T. Shimizu and M. Masuda, J. Am. Chem. Soc., 1997, 119, 2812-2818.

39 L. Frkanec, M. Jokić, J. Makarević, K. Wolsperger and M. Žinić, J. Am. Chem. Soc., 2002, 124, 9716-9717.

40 S. Lang, Curr. Opin. Colloid Interface Sci., 2002, 7, 12-20.

41 R. Marchant and I. M. Banat, Trends Biotechnol., 2012, 30, 558-565.

M. Nitschke and S. G. V. A. O. Costa, Trends Food Sci. Technol., 2007, 18, 252-259.

C. N. Mulligan, Curr. Opin. Colloid Interface Sci., 2009, 14, 372-378.

D. Kitamoto, T. Morita, T. Fukuoka, M. Konishi and T. Imura, Curr. Op. Coll. Interf. Sci., 2009, 14, 315-328.

45 C. N. Mulligan, Environ. Pollut., 2005, 133, 183-198.

S. S. Cameotra and R. S. Makkar, Curr. Opin. Microbiol., 2004, 7, 262-266.

S. Lodens, M. De Graeve, S. Roelants, S. De Maeseneire and W. Soetaert, in Synthetic Biology - Series Methods in Molecular Biology, ed. Jeff Braman, Springer, 2018.

48 L. Van Renterghem, S. L. K. W. Roelants, N. Baccile, K. Uytersprot, M. C. Taelman, B. Everaert, S. Mincke, S. Ledegen, S. Debrouwer, K. Scholtens, C. V. Stevens and W. Soetaert, Biotechnol. Bioeng., 2018, DOI: 10.1002/bit.26539.

49 N. Baccile, F. Babonneau, I. M. Banat, K. Ciesielska, A.-S. Cuvier, B. Devreese, B. Everaert, H. Lydon, R. Marchant, C. A. Mitchell, S. Roelants, L. Six, E. Theeuwes, G. Tsatsos, G. E. Tsotsou, B. Vanlerberghe, I. N. A. Van Bogaert and W. Soetaert, ACS Sustain. Chem. Eng., 2017, 5, 1186-1198.

50 E. I. P. Delbeke, S. L. K. W. Roelants, N. Matthijs, B. Everaert, W. Soetaert, T. Coenye, K. M. Van Geem and C. V. Stevens, Ind. Eng. Chem. Res., 2016, 55, 7273-7281.

51 S. L. K. W. Roelants, L. Van Renterghem, K. Maes, B. Everaert, E. Redant, B. Vanlerberghe, S. Demaeseneire and W. Soetaert, in Microbial Biosurfactants and their Environmental and Industrial Applications, eds. I. M. Banat and R. Thavasi, CRC Press, 2018.

52 I. N. A. Van Bogaert, D. Buyst, J. C. Martins, S. L. K. W. Roelants and W. K. Soetaert, Biotechnol. Bioeng., 2016, 113, 2644-2651.

53 S. L. K. W. Roelants, K. Ciesielska, S. L. De Maeseneire, H. Moens, B. Everaert, S. Verweire, Q. Denon, B. Vanlerberghe, I. N. A. Van Bogaert, P. Van der Meeren, B. Devreese and W. Soetaert, Biotechnol. Bioeng., 2016, 113, 550-559.

54 S. L. K. W. Roelants, K. M. J. Saerens, T. Derycke, B. Li, Y. C. Lin, Y. Van de Peer, S. L. De Maeseneire, I. N. A. Van Bogaert and W. Soetaert, Biotechnol. Bioeng., 2013, 110, 2494-2503.

55 A.-S. Cuvier, J. Berton, C. V Stevens, G. C. Fadda, F. Babonneau, I. N. a Van Bogaert, W. Soetaert, G. Pehau-Arnaudet and N. Baccile, Soft Matter, 2014, 10, 3950-9.

56 A. S. Cuvier, F. Babonneau, J. Berton, C. V. Stevens, G. C. Fadda, I. Genois, P. Le Griel, G. Péhau-Arnaudet and N. Baccile, Chem. - An Asian J., 2015, 10, 2419-2426.

57 N. Baccile, A.-S. Cuvier, S. Prévost, C. V Stevens, E. Delbeke, J. Berton, W. Soetaert, I. N. A. Van Bogaert and S. Roelants, Langmuir, 2016, 32, 10881-10894.

58 N. Baccile, M. Selmane, P. Le Griel, S. Prévost, J. Perez, C. V. Stevens, E. Delbeke, S. Zibek, M. Guenther, W. Soetaert, I. N. A. Van Bogaert and S. Roelants, Langmuir, 2016, 32, 6343-6359. 
http://www.esrf.eu/home/UsersAndScience/Experiments/MX/About_our_beamlines/bm2 9.html, .

60 P. Pernot, A. Round, R. Barrett, A. De Maria Antolinos, A. Gobbo, E. Gordon, J. Huet, J. Kieffer, M. Lentini, M. Mattenet, C. Morawe, C. Mueller-Dieckmann, S. Ohlsson, W. Schmid, J. Surr, P. Theveneau, L. Zerrad and S. McSweeney, J. Synchrotron Radiat., 2013, 20, 660-664.

61 A. Round, F. Felisaz, L. Fodinger, A. Gobbo, J. Huet, C. Villard, C. E. Blanchet, P. Pernot, S. McSweeney, M. Roessle, D. I. Svergun and F. Cipriani, Acta Crystallogr. Sect. $D, 2015,71,67-75$.

62 G. Ashiotis, A. Deschildre, Z. Nawaz, J. P. Wright, D. Karkoulis, F. E. Picca and J. Kieffer, J. Appl. Crystallogr., 2015, 48, 510-519.

63 N. Baccile, V. Cristiglio, I. Grillo, A. Lassenberger and E. Reimhult, in Institut LaueLangevin (ILL), Institut Laue-Langevin (ILL), 2017.

64 J. Schindelin, I. Arganda-Carreras, E. Frise, V. Kaynig, M. Longair, T. Pietzsch, S. Preibisch, C. Rueden, S. Saalfeld, B. Schmid, J.-Y. Tinevez, D. J. White, V. Hartenstein, K. Eliceiri, P. Tomancak and A. Cardona, Nat Meth, 2012, 9, 676-682.

65 http://nmr.cemhti.cnrs-orleans.fr/dmfit, .

66 D. Massiot, F. Fayon, M. Capron, I. King, S. Le Calvé, B. Alonso, J. O. Durand, B. Bujoli, Z. Gan and G. Hoatson, Magn. Reson. Chem., 2002, 40, 70-76.

67 E. Choppe, F. Puaud, T. Nicolai and L. Benyahia, Carbohydr. Polym., 2010, 82, 12281235.

68 I. W. Hamley, Macromolecules, 2008, 41, 8948-8950.

69 H. Cui, T. Muraoka, A. G. Cheetham and S. I. Stupp, Nano Lett., 2009, 9, 945-951.

70 L. Ziserman, H. Y. Lee, S. R. Raghavan, A. Mor and D. Danino, J. Am. Chem. Soc., 2011, 133, 2511-2517.

71 J. H. Jung, S. Shinkai and T. Shimizu, Chem. - A Eur. J., 2002, 8, 2684-2690.

72 C. Tanford, The hydrophobic effect: Formation of micelles and biological membranes, Wiley-Interscience, 1973.

73 T. G. Barclay, K. Constantopoulos and J. Matisons, Chem. Rev., 2014, 114, 10217-10291.

74 R. Oda, F. Artzner, M. Laguerre and I. Huc, J. Am. Chem. Soc., 2008, 130, 14705-14712.

75 N. Kameta, M. Masuda, H. Minamikawa and T. Shimizu, Langmuir, 2007, 23, 46344641.

76 M. Masuda, K. Yoza and T. Shimizu, Carbohydr. Res., 2005, 340, 2502-2509.

77 J. H. Jung, G. John, M. Masuda, K. Yoshida, S. Shinkai and T. Shimizu, Langmuir, 2001, 17, 7229-7232.

78 V. Castelletto, I. W. Hamley, R. a Hule and D. Pochan, Angew. Chem. Int. Ed. Engl., 2009, 48, 2317-2320.

79 A. K. Mehta, K. Lu, W. S. Childers, Y. Liang, S. N. Dublin, J. Dong, J. P. Snyder, S. V. Pingali, P. Thiyagarajan and D. G. Lynn, J. Am. Chem. Soc., 2008, 130, 9829-9835.

80 E. T. Pashuck and S. I. Stupp, J. Am. Chem. Soc., 2010, 132, 8819-8821.

81 S. R. Raghavan, Langmuir, 2009, 25, 8382-8385.

82 P.-G. de Gennes, Macromolecules, 1976, 9, 587-593.

83 R. de Rooij, D. van den Ende, M. H. G. Duits and J. Mellema, Phys. Rev. E, 1994, 49, 3038-3049.

84 P. J. Flory, Principles of polymer chemistry, Cornell University Press, Ithaca, NY, NY, 1953. 
85 W. W. Graessley, Polymeric liquids and networks : dynamics and rheology, Garland Science, London; New York, 2008.

86 J. R. Stokes, in Food biopolymer gels, microgel and nanogel structures, formation and rheology, eds. B. Bhandari and Y. H. Roos, Wiley-Blackwell, New Jersey, 2012, pp. 151176.

87 F. Horkay, J. Magda, M. Alcoutlabi, S. Atzet and T. Zarembinski, Polymer (Guildf)., 2010, 51, 4424-4430.

88 S. Q. Chen, P. Lopez-Sanchez, D. Wang, D. Mikkelsen and M. J. Gidley, Food Hydrocoll., 2018, 81, 87-95.

89 J. Kierfeld, K. Baczynski, P. Gutjahr and R. Lipowsky, Semiflexible Polymers and Filaments: From Variational Problems to Fluctuations, 2008, vol. 1002.

$90 \quad$ X. Y. Liu and P. D. Sawant, Appl. Phys. Lett., 2001, 79, 3518-3520.

91 J. L. Li and X. Y. Liu, Adv. Funct. Mater., 2010, 20, 3196-3216.

92 R. Yu, N. Lin, W. Yu and X. Y. Liu, CrystEngComm, 2015, 17, 7986-8010.

93 N. Baccile, F. Babonneau, J. Jestin, G. Péhau-Arnaudet and I. Van Bogaert, ACS Nano, 2012, 6, 4763-4776.

94 J. Penfold, M. Chen, R. K. Thomas, C. Dong, T. J. P. Smyth, A. Perfumo, R. Marchant, I. M. Banat, P. Stevenson, A. Parry, I. Tucker and I. Grillo, Langmuir, 2011, 27, 8867-8877.

95 O. Glatter and O. Kratky, Small Angle X-ray Scattering, Academic Press, London, 1982.

96 A. Guinier, Ann. Phys. (Paris)., 1939, 11, 161-237.

97 P. Terech, J. Colloid Interface Sci., 1985, 107, 244-255.

98 D. J. Adams, M. F. Butler, W. J. Frith, M. Kirkland, L. Mullen and P. Sanderson, Soft Matter, 2009, 5, 1856.

99 M. Tena-Solsona, B. Escuder, J. F. Miravet, V. Castelletto, I. W. Hamley and A. Dehsorkhi, Chem. Mater., 2015, 27, 3358-3365.

100 G. Feio and J. P. Cohen-Addad, J. Polym. Sci. Part B Polym. Phys., 1988, 26, 389-412.

101 P. Dhasaiyan, P. Le Griel, S. Roelants, E. Redant, I. N. A. Van Bogaert, S. Prevost, B. L. V Prasad and N. Baccile, ChemPhysChem, 2017, 18, 643-652.

102 M. Avrami, J. Chem. Phys. III J. Chem. Phys. J. Chem. Phys. Kinet. Heterog. Nucleation J. Chem. Phys. I. Interfacial Free Energy J. Chem. Phys. J. Chem. Phys., 1940, 81, 212198.

103 M. Avrami, J. Chem. Phys., 1941, 9, 177-184.

104 J. A. Lopes-da-Silva and J. A. P. Coutinho, Energy and Fuels, 2007, 21, 3612-3617.

105 J. F. Toro-Vazquez, E. Dibildox-Alvarado, M. Charó-Alonso, V. Herrera-Coronado and C. a. Gómez-Aldapa, J. Am. Oil Chem. Soc., 2002, 79, 855-866.

106 J. Dudowicz, J. F. Douglas and K. F. Freed, J. Chem. Phys., 2009, 130, 1-8.

107 E. B. Stukalin, J. F. Douglas and K. F. Freed, J. Chem. Phys., 2008, 129, 1-17.

108 D. a. S. Grahame, C. Olauson, R. S. H. Lam, T. Pedersen, F. Borondics, S. Abraham, R. G. Weiss and M. a. Rogers, Soft Matter, 2011, 7, 7359.

109 M. A. Rogers, S. Abraham, F. Bodondics and R. G. Weiss, Cryst. Growth Des., 2012, 12, 5497-5504.

Figure S 1

Figure $S 2$

Figure $S 3$

Figure $S 4$ 
Figure S 5

Figure S 6

Figure $\mathbf{S} 7$

Figure S 8

Figure S 9

Figure $S 10$

Figure S 11

Figure S 12

Figure S 13 


\title{
Electronic Supporting Information
}

\section{(ESI)}

\section{Bio-based glyco-bolaamphiphile forms a temperature-responsive hydrogel with tunable elastic properties}

\author{
Niki Baccile, ${ }^{\mathrm{a}}$ Lisa Van Renterghem,, Patrick Le Griel, ${ }^{\mathrm{a}}$ Guylaine Ducouret, ${ }^{\mathrm{c}}$ Martha \\ Brennich, ${ }^{\text {d Viviana Cristiglio, }}{ }^{\text {e }}$ Sophie Roelants, ${ }^{\text {b,f }}$ Wim Soetaert ${ }^{\text {b }}$ \\ a Sorbonne Université, Centre National de la Recherche Scientifique, Laboratoire de Chimie de la \\ Matière Condensée de Paris, LCMCP, F-75005 Paris, France \\ ${ }^{\mathrm{b}}$ Ghent University, Centre for Industrial Biotechnology and Biocatalysis (InBio.be), Faculty of \\ Bioscience Engineering, Coupure Links 653, Ghent, Oost-Vlaanderen, BE 9000 \\ c Laboratoire Sciences et Ingénierie de la Matière Molle, CNRS UMR 7615, ESPCI Paris, PSL \\ Research University, 10 rue Vauquelin, F-75231 Paris cedex 05, France \\ ${ }^{\mathrm{d}}$ European Molecular Biology Laboratory, Synchrotron Crystallography Group, 71 Avenue des \\ Martyrs, 38042 Grenoble, France \\ e Institut Laue-Langevin, Grenoble, Beamline D16, Cedex 9, 38042, Grenoble, France \\ ${ }^{\mathrm{f}}$ Bio Base Europe Pilot Plant, Rodenhuizekaai 1, Ghent, Oost-Vlaanderen, BE 9000
}



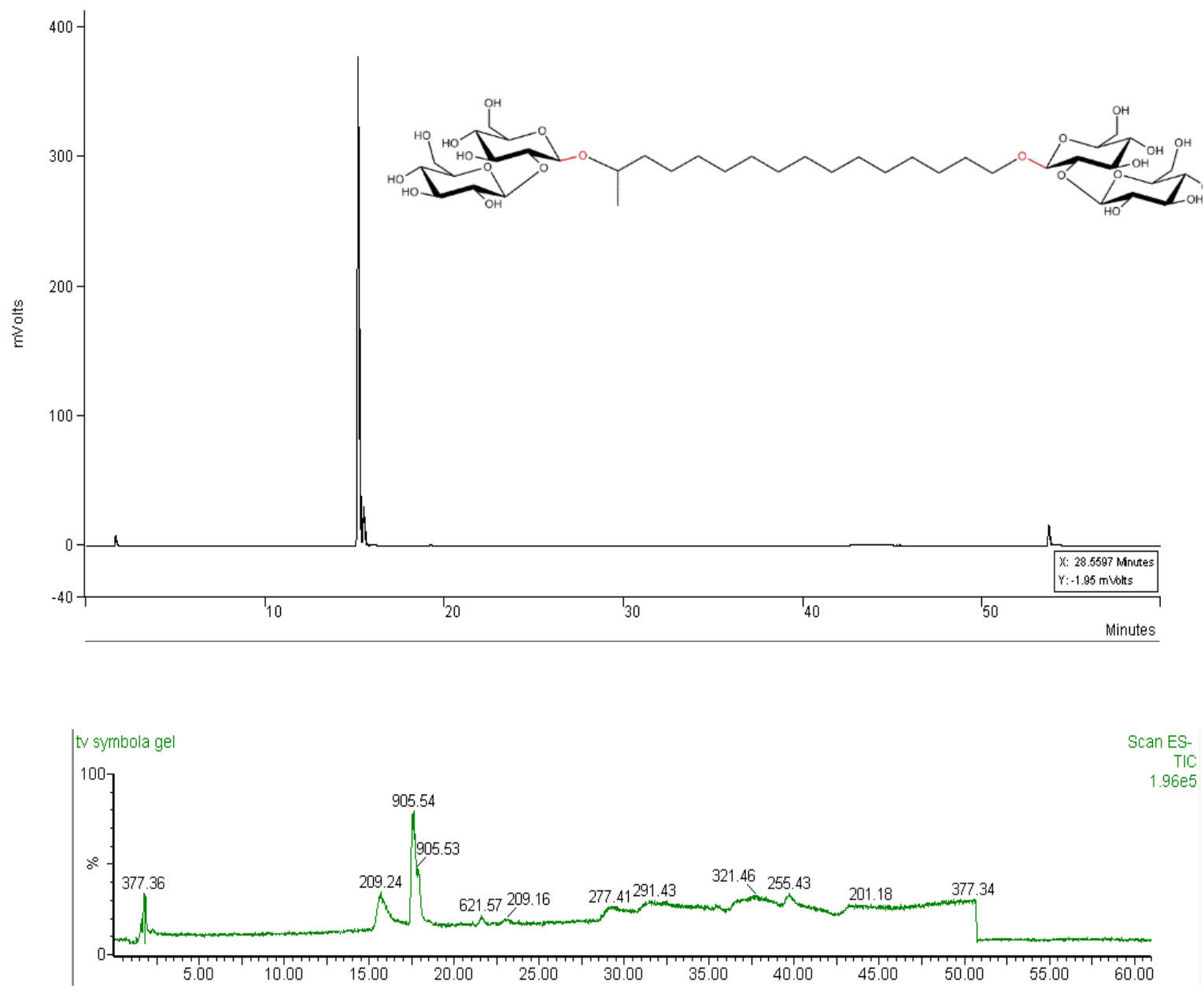

Figure S 1 - HPLC-ELSD (top) and LC-MS (bottom) chromatograms of the symmetrical bola C16:0 sophoroside (SS) purified batch. The peak at 15 or 17.5 minutes ( $\mathrm{m} / \mathrm{z}$ value of 905$)$ corresponds with the sBola C16:0 SS, for HPLC-ELSD and LC-MS respectively. 

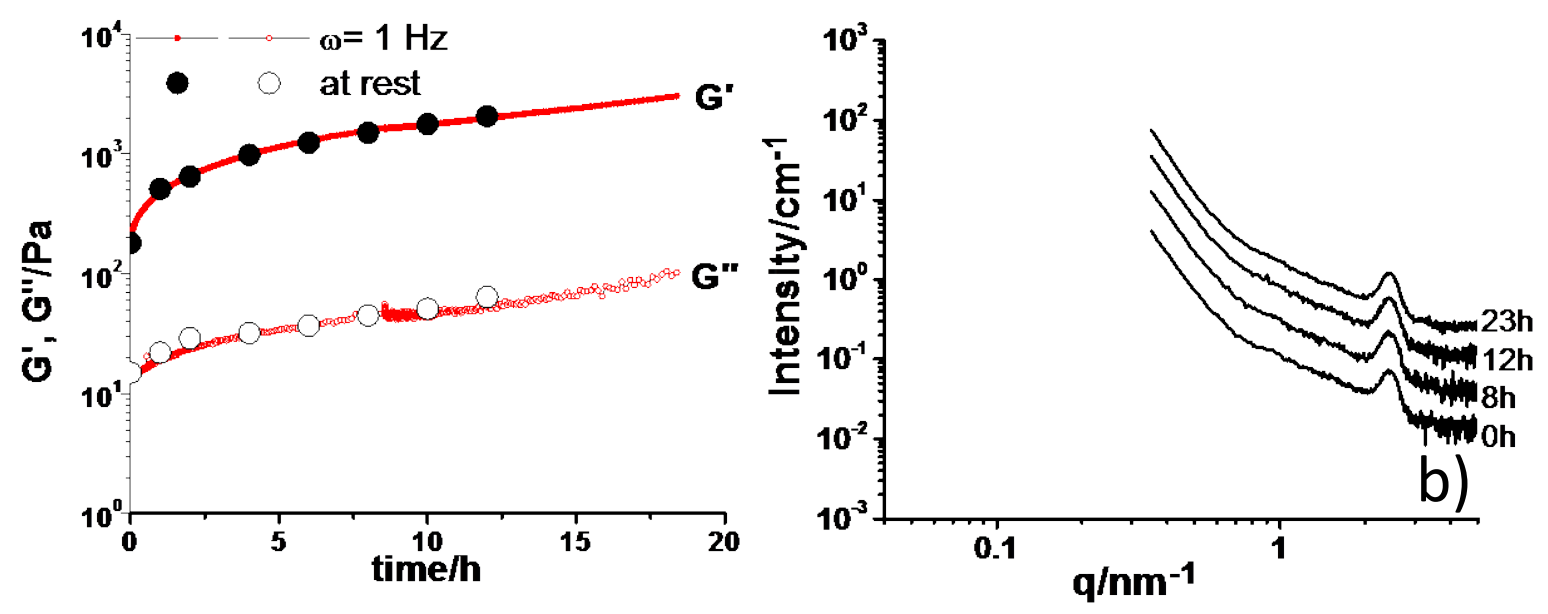

Figure S 2 - a) Time evolution of the storage and loss moduli with time at $\mathrm{T}=25^{\circ} \mathrm{C}, \mathrm{C}=3 \mathrm{wt} \%$, and stress, $\tau=1$ Pa. Full symbols refer to a sampling rate of 560 points/h under a frequency, $f=1 \mathrm{~Hz}$; empty symbols refer to a sample at rest, sampled at $\mathrm{t}=0 \mathrm{~h}, 1 \mathrm{~h}, 2 \mathrm{~h}$ and then every $2 \mathrm{~h}$ (f=1 Hz during analysis). b) Time-dependent SANS experiments recorded at $\mathrm{C}=3 \mathrm{wt} \%$ and $\mathrm{T}=25^{\circ} \mathrm{C}$.

The stability of the hydrogel over time has been tested by repeating the experiment under two different conditions: 1) the gel, kept at rest in the geometry, is subjected to a short solicitations, as shown on Figure $\mathrm{S} 2 ; 2$ ) the gel is submitted to a continuous oscillating time sweep ( $\mathrm{f}=1 \mathrm{~Hz}$ and $\tau=1 \mathrm{~Pa}$ ). As shown on Figure $\mathrm{S} 2 \mathrm{a}$, the two methods provide data points which are superimposable throughout the time-scale, indicating that the constant solicitation does not alter the gel formation/structuration during the experiment. 


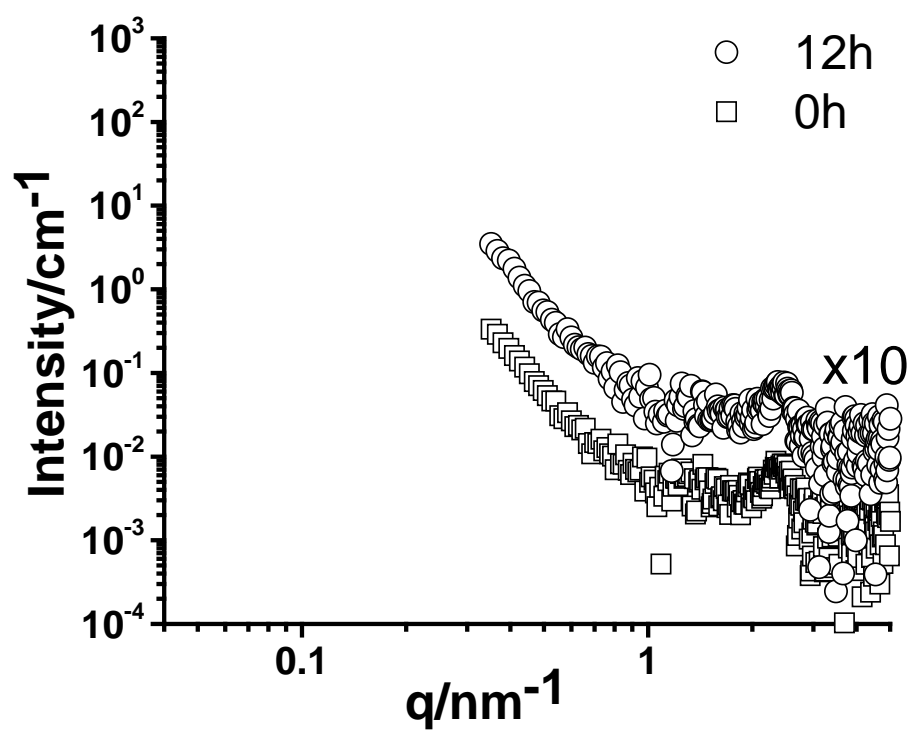

Figure S 3 - SANS experiments collected on sBola C16:0 SS at 0.3 wt $\%$ at $T=25^{\circ} \mathrm{C}$ at $\mathrm{t}=\mathbf{0 ~ h}$ and $\mathrm{t}=12 \mathrm{~h}$. 


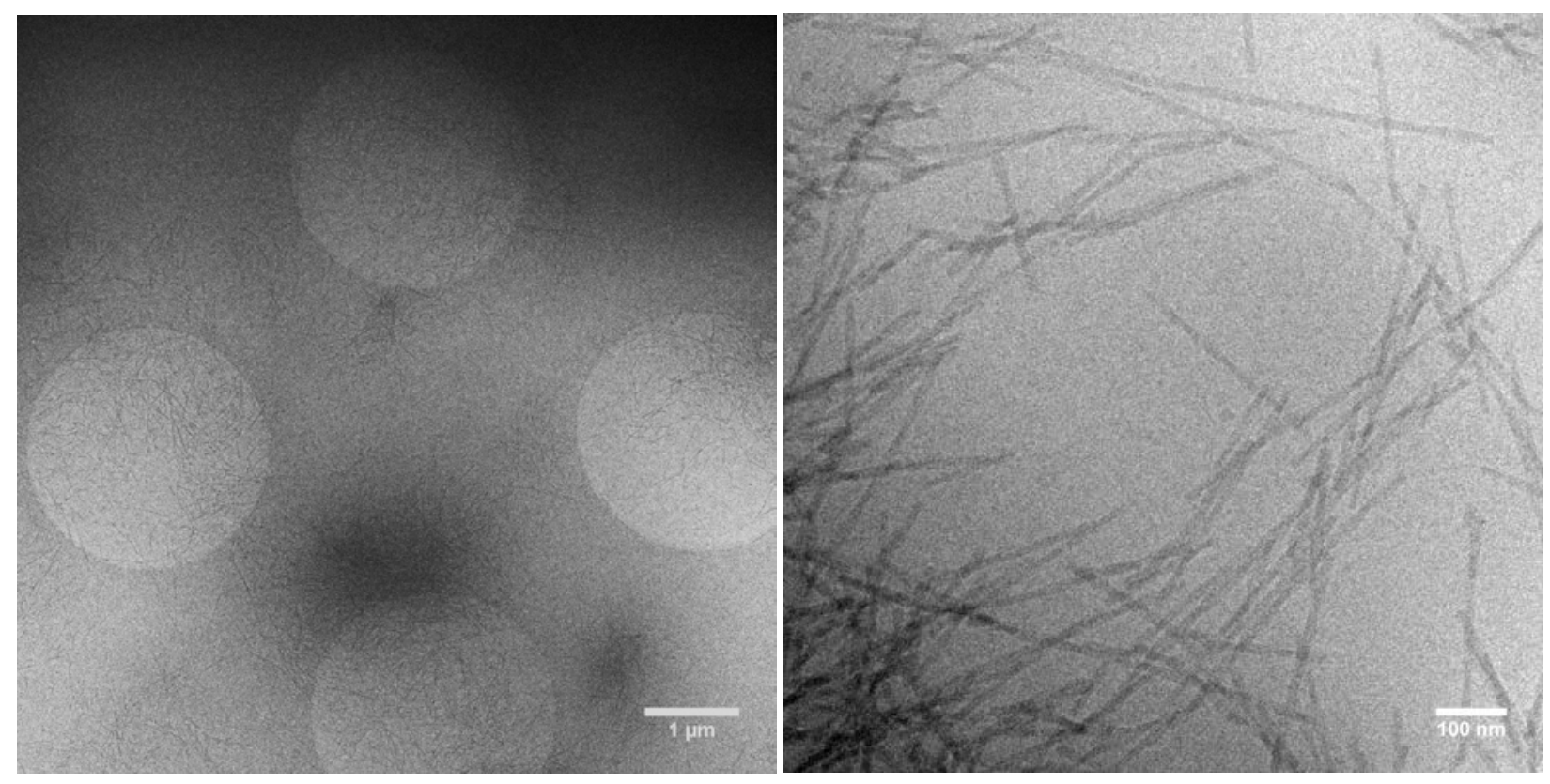

Figure S 4 - Cryo-TEM micrographs collected on sBola C16:0 SS at $3 \mathrm{wt} \%$ at $\mathrm{T}=25^{\circ} \mathrm{C}$ and $\mathrm{t}=\mathbf{0} \mathrm{h}$ 

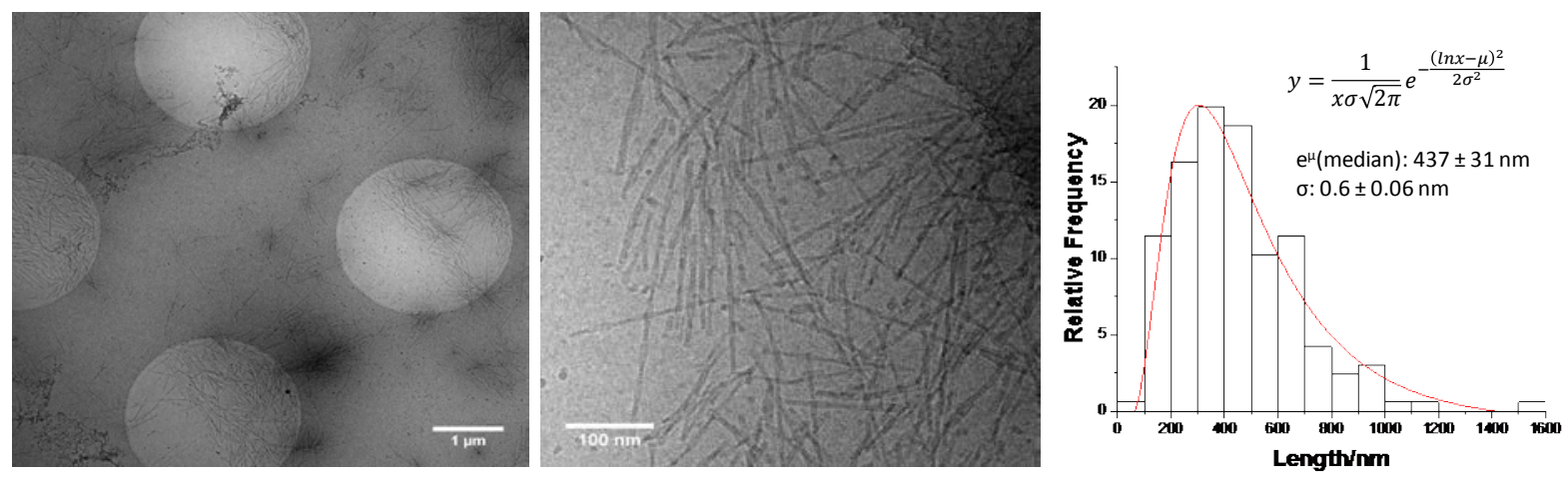

Figure S 5 - Cryo-TEM micrographs collected on sBola C16:0 SS at $1 \mathrm{wt} \%$ at $\mathrm{T}=25^{\circ} \mathrm{C}$ and $\mathrm{t}=0 \mathrm{~h}$. The righthand image shows the length distribution, fitted using a log-normal function. Data have been treated using the built-in function within the Origin Pro 2015 software package. 

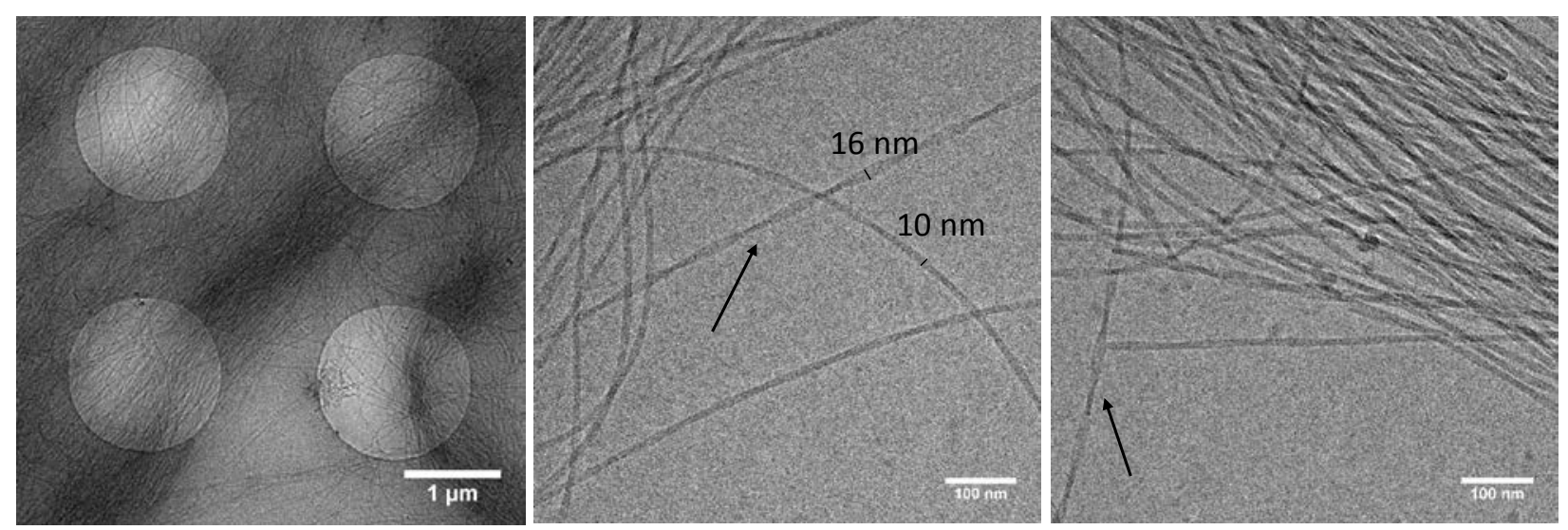

Figure S 6 - Cryo-TEM micrographs collected on sBola C16:0 SS at 1 wt $\%$ at $\mathrm{T}=25^{\circ} \mathrm{C}$ and $\mathrm{t}=15 \mathrm{~h}$. Arrows point at twisted ribbons.

Figure S 4, Figure S 5 and Figure S 6 show that morphology changes are not responsible for the increase in the mechanical properties of the hydrogel. The low-magnification cryo-TEM images for the $3 \mathrm{wt} \%$ (Figure S 4) and $1 \mathrm{wt} \%$ (Figure S 5) samples at $\mathrm{t}=0 \mathrm{~h}$ obviously show a higher density of the fibers in the $3 \mathrm{wt} \%$ sample, which can explain the higher storage modulus at $\mathrm{t}=0 \mathrm{~h}$ for this sample. However, the time-dependent increase of $\mathrm{G}^{\prime}$ can be explained by an increase in length of the fibers themselves over time, thus confirming from a visual point of view the analysis of the time-dependent evolution of $G^{\prime}(C)$. At $t=0 h$, one can fit the length distribution of the 1 $\mathrm{wt} \%$ sample with a log-normal function having mean and standard deviation respectively of $\mu=$ $436.6 \pm 30.8 \mathrm{~nm}$ and $\sigma=0.6 \pm 0.1$ (Figure S 5). Despite the limited number of sampled population ( $N=160)$, due to the strong aggregation of the fibers on the cryo-TEM grid, a factor which made it impossible to analyze the length distribution at $3 \mathrm{wt} \%$, one should retain the presence of fibers with an overall finite size when the sample is prepared. On the contrary, the length of the fibers strongly increases and it becomes “infinite” (with respect to the cross-section) after 15 hours (lowmagnification image in Figure S 6. Cryo-TEM confirms the rheology assumptions: fiber growth and entanglement are responsible for the gel formation and its elastic properties. 


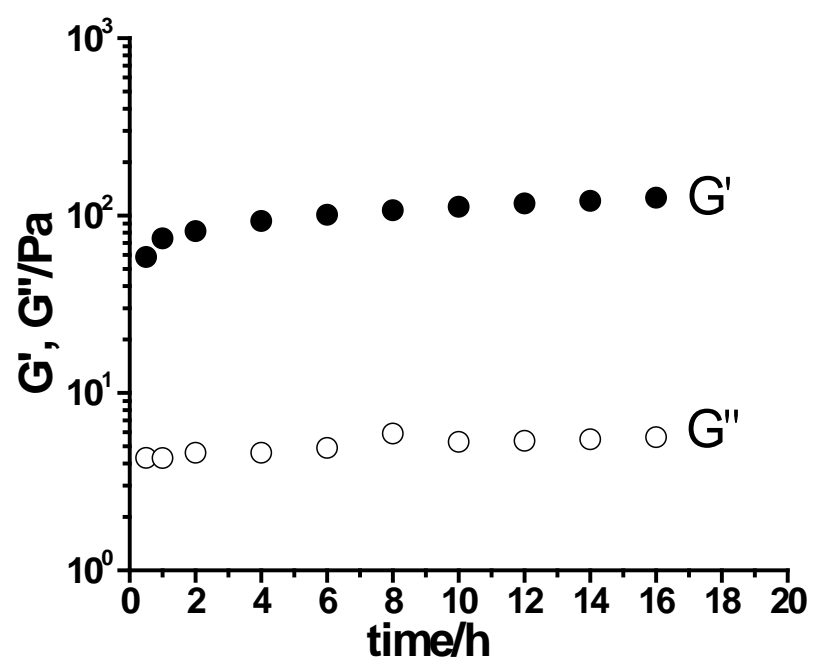

Figure S 7 - Measurement of the time-dependent $(f=1 \mathrm{~Hz}, \tau=1 \mathrm{~Pa})$ storage and loss moduli for sBola $\mathrm{C16}$ :0 SS at $\mathrm{C}=3 \mathrm{wt} \%$ and $\mathrm{T}=5^{\circ} \mathrm{C}$ 

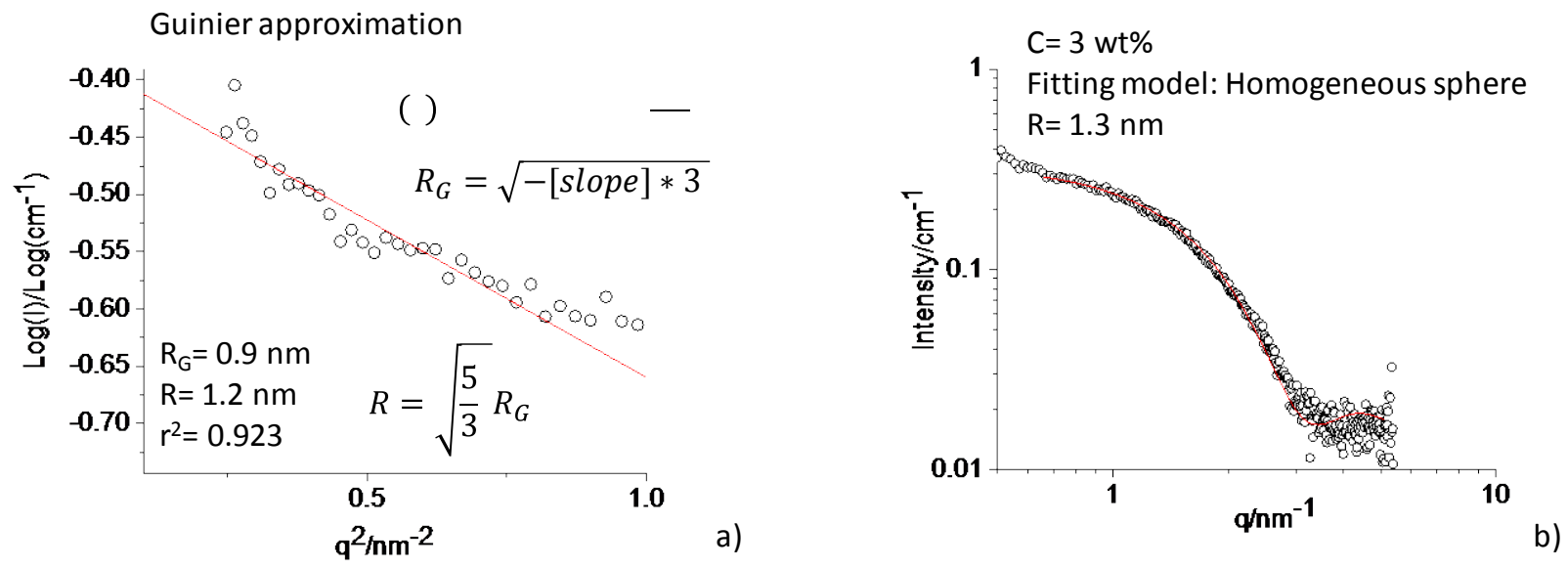

Figure $S 8$ - a) Guinier plot $\log [\mathrm{I}(\mathrm{q})]$ vs $\mathbf{q}^{2}$ at $\mathbf{q}^{<} 1 \mathrm{~nm}^{-1}$ (Guinier approximation for the whole particle $)^{1,2}$ corresponding to the SANS profile of sample at $\mathrm{C}=3 \mathrm{wt} \%$ and $\mathrm{T}=25^{\circ} \mathrm{C}$, presented in Figure $3 \mathrm{c}$ in the main manuscript. b) Fit of the SANS profile corresponding to the same sample. The fit has been done with the SasView 3.1.2 software package (https://www.sasview.org).

The fit in Figure S 8b is intended to provide another way to estimate the radius of the micelles and it is not intended to precisely describe the structure of the micelle, most likely expected to be core-shell, as found in similar system. ${ }^{3}$ For this reason, we have used a simple homogeneous sphere form factor model with the following parameters:

Scattering Length Density (SLD) of the solvent $\left(\mathrm{D}_{2} \mathrm{O}\right): 6.34 * 10^{-4} \mathrm{~nm}^{-2}$ (fixed).

Scale: 0.03 (fixed). In the model proposed by SasView, this parameter is equivalent to the volume fraction, which corresponds to $3 \mathrm{wt} \%$.

SLD of the sphere: $2.97 * 10^{-4} \mathrm{~nm}^{-2}$ (fitted). The SLD of the micelle is expected to be contained between $\sim 4 * 10^{-4} \mathrm{~nm}^{-2}$, corresponding to the SLD level of glucose in $\mathrm{D}_{2} \mathrm{O}$ (including a full OH/OD exchange), and $\sim 10^{-5} \mathrm{~nm}^{-2}$, corresponding to the level of an aliphatic chain in water. The SLD values are estimated using the SLD calculator tool in the 3.1.2 version of Sasview software.

Radius of the sphere: $1.3 \mathrm{~nm}$ (fitted).

Background: $0.017 \mathrm{~cm}^{-1}$ (adjusted through fitting).

1. O. Glatter and O. Kratky, Small Angle X-ray Scattering, Academic Press, London, 1982

2. A. Guinier, Ann. Phys. (Paris), 1939, 11, 161-237

3. S. Manet et al., J. Phys. Chem. B, 2015, 119, 13113 

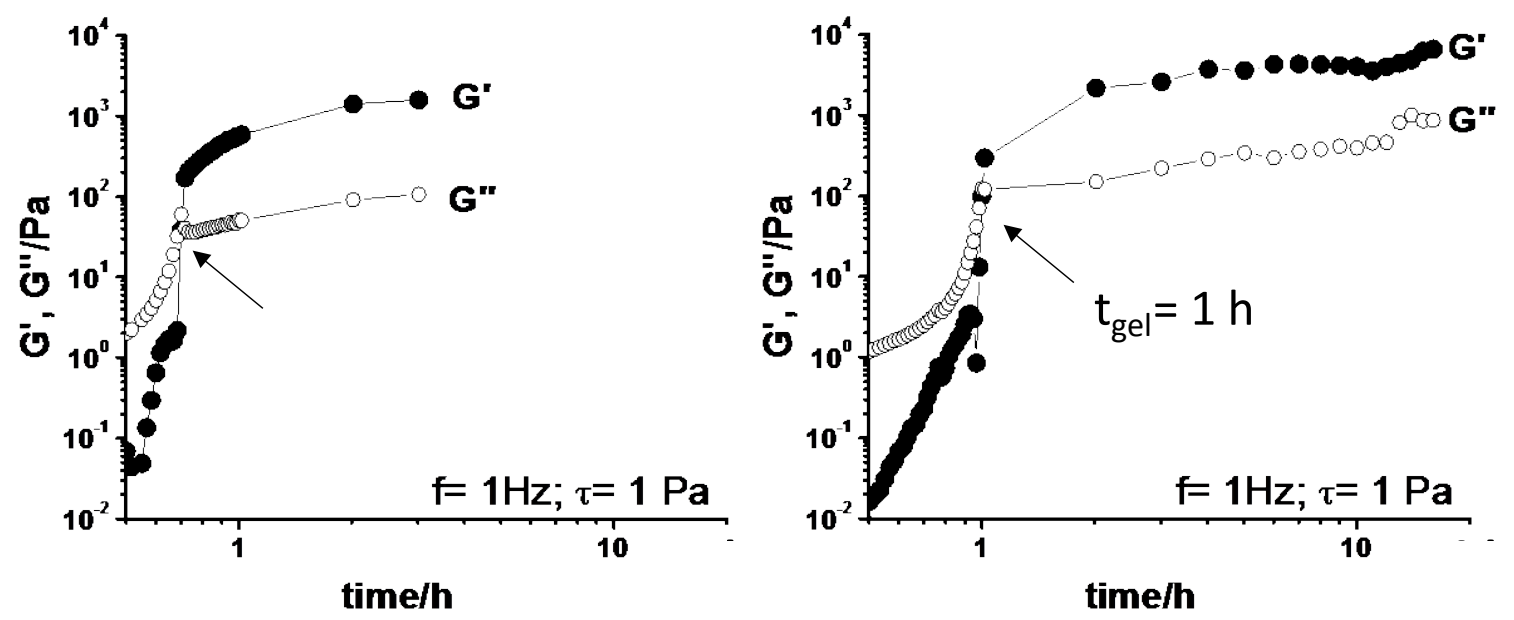

Figure $S 9$ - Time-dependent evolution of the storage and loss moduli $(\mathrm{f}=1 \mathrm{~Hz}, \tau=1 \mathrm{~Pa})$ recorded on a sBola C16:0 SS hydrogel $(C=3 \mathrm{wt} \%)$ heated at $\mathrm{T}=35^{\circ} \mathrm{C}$ for $10 \mathrm{~min}$ and brought to $\mathrm{T}=25^{\circ} \mathrm{C}$. Time scale starts at $\mathrm{T}=$ $25^{\circ} \mathrm{C}$. a) and b) are two different samples, recorded on the same system so to show the fluctuations in terms of tgel. 

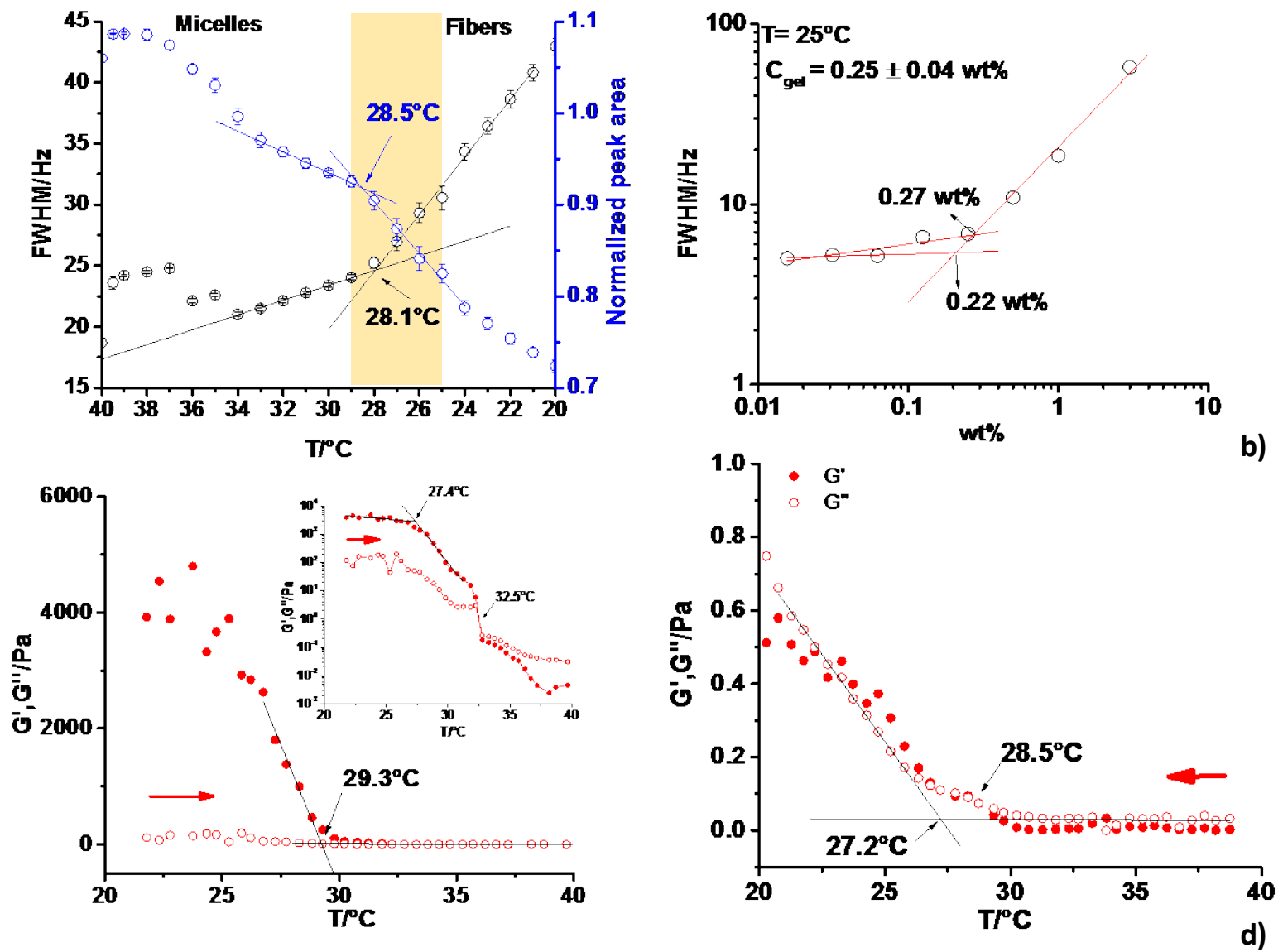

Figure $\mathrm{S} 10-a)$ Measurement of $T_{\text {gel }}$ at $C=3 \mathrm{wt} \%$ by following the Full Width at Half Maximum (FWHM) and integrated normalized area of the ${ }^{1} \mathrm{H}$ NMR signal of the alkyl chain of sBola C16:0 SS at $\delta=1.3 \mathrm{ppm}$. b) Measurement of $\mathrm{C}_{\text {gel }}$ at $\mathrm{T}=25^{\circ} \mathrm{C}$ by following the FWHM of the ${ }^{1} \mathrm{H}$ NMR signal of the alkyl chain of sBola C16:0 SS at $\delta=1.3 \mathrm{ppm}$. Linear regression is used in both experiments to determine the intersection point. For $\mathrm{C}_{\text {gel, }}$ two points have been retained. c-d) Measurement of $\mathrm{T}_{\text {gel }}$ at $\mathrm{C}=3 \mathrm{wt} \%$ by rheology $(\tau=0.6 \mathrm{~Pa}, \mathrm{f}=1 \mathrm{~Hz})$. In c), a hydrogel is formed at $\mathrm{T}=20^{\circ} \mathrm{C}$ during $1 \mathrm{~h}$ at rest. Next, temperature is increased with a rate of $0.5^{\circ} \mathrm{C} / \mathrm{min}$; methodology for the evaluation of $T_{\text {gel }}$ are shown in the figure and the corresponding inset, representing the data in a $\log$-lin scale. In d), the solution is heated at $\mathrm{T}=40^{\circ} \mathrm{C}$ for $5 \mathrm{~min}$ and temperature is subsequently lowered at a rate of $0.5^{\circ} \mathrm{C} / \mathrm{min}$; $T_{\text {gel }}$ is evaluated both at the $G^{\prime} / G^{\prime \prime}$ intersection point and at the inflection point, as shown in the figure. 

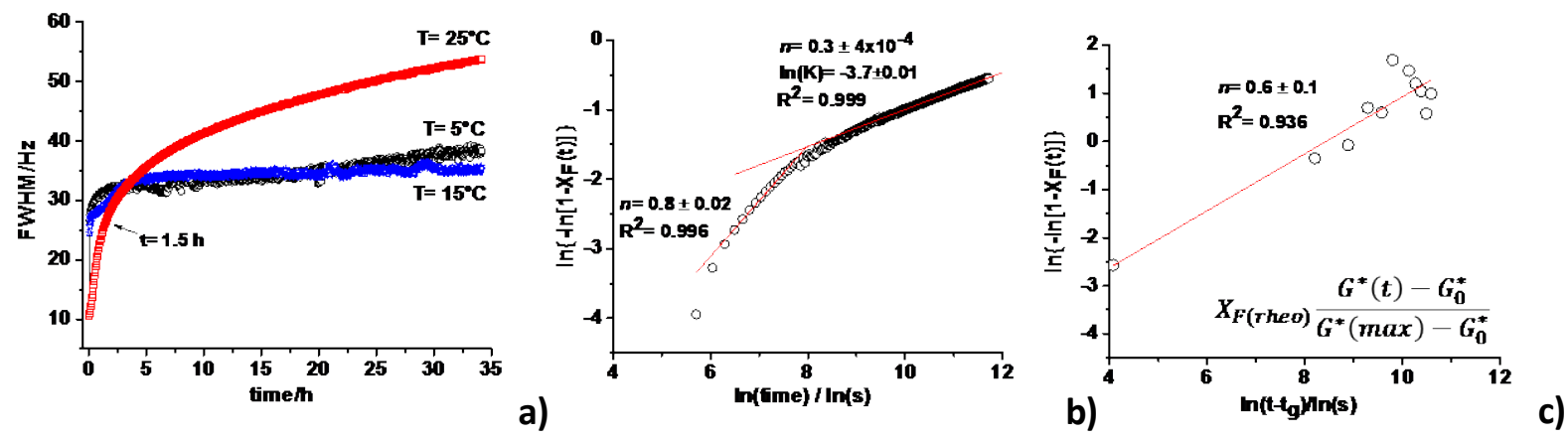

Figure S 11 - a) Time and temperature-dependent evolution of the Full Width at Half Maximum (FWHM) of the $\mathrm{C16}$ alkyl resonance at $1.3 \mathrm{ppm}$ in the ${ }^{1} \mathrm{H}$ NMR experiments. The data are collected after after a sol-gel transition from $\mathrm{T}=40^{\circ} \mathrm{C}$ to the indicated value of the temperature $\left(25^{\circ} \mathrm{C}, 15^{\circ} \mathrm{C}, 5^{\circ} \mathrm{C}\right)$. b) Avrami plots showing the dependency of the $\ln \left\{-\ln \left[\left(1-X_{F}\right)\right]\right\}$ on $\ln (t)$, based on NMR signal decay of the alkyl resonance at $1.3 \mathrm{ppm}$ (Figure 6b). c) Avrami plot against $\ln \left(t-t_{g}\right)$ based on the rheological property G* (Figure 4). For the definition of $X_{F}$ in NMR and rheology, please refer to main text. Both data in $b$ ) and c) are recorded at $\mathrm{T}=25^{\circ} \mathrm{C}$ after a sol-gel transition from $\mathrm{T}=40^{\circ} \mathrm{C}$. 

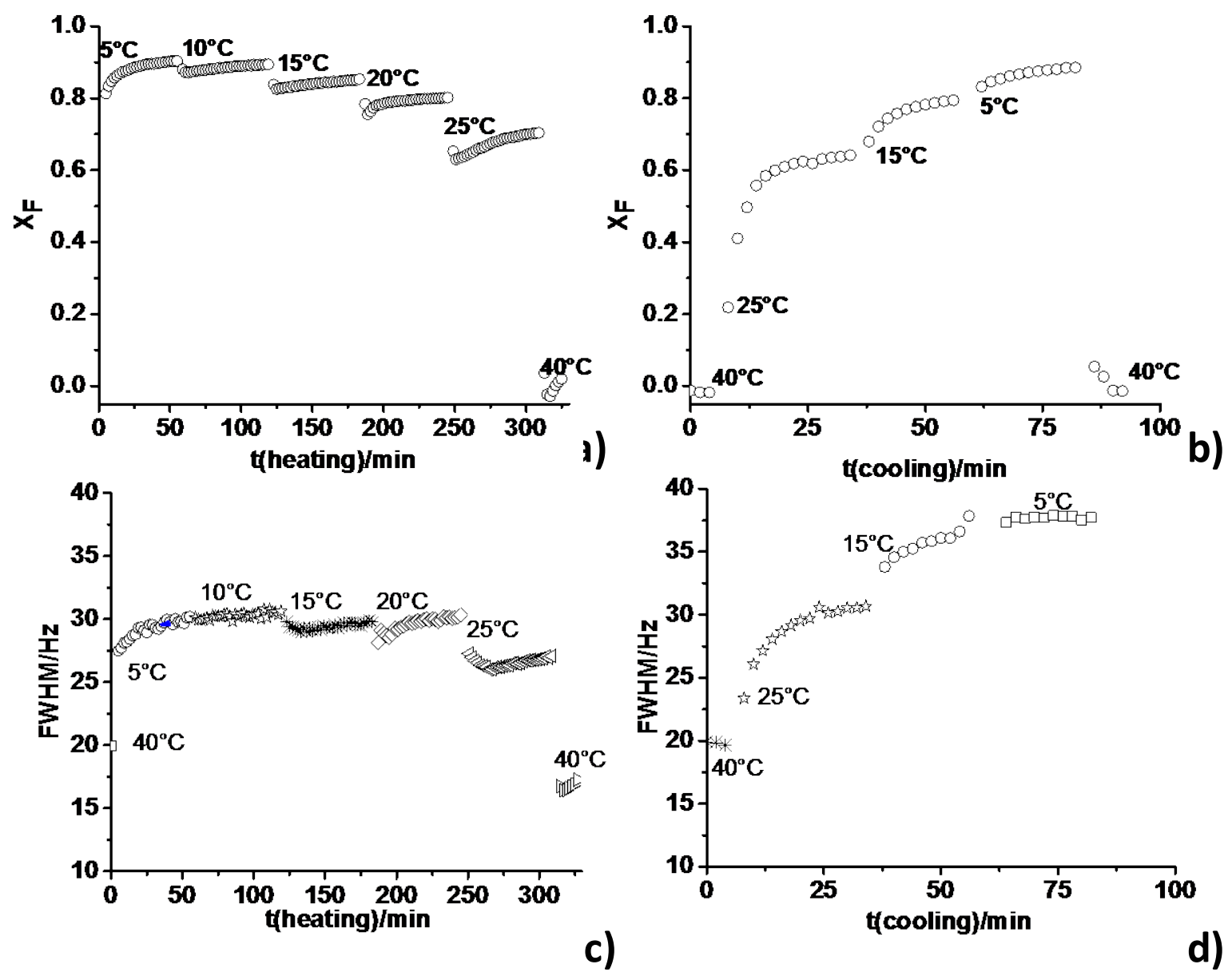

Figure $S 12$ - a-d) Time and temperature evolution of $X_{F}$ and FWHM under cooling and heating conditions and measured from the signal of the alkyl chain of sBola C16:0 SS at $1.3 \mathrm{ppm}$ by ${ }^{1} \mathrm{H}$ NMR. In a), the system at $t=0$ min is meant to be at $T=40^{\circ} \mathrm{C}$ and $X_{F}=0$. 

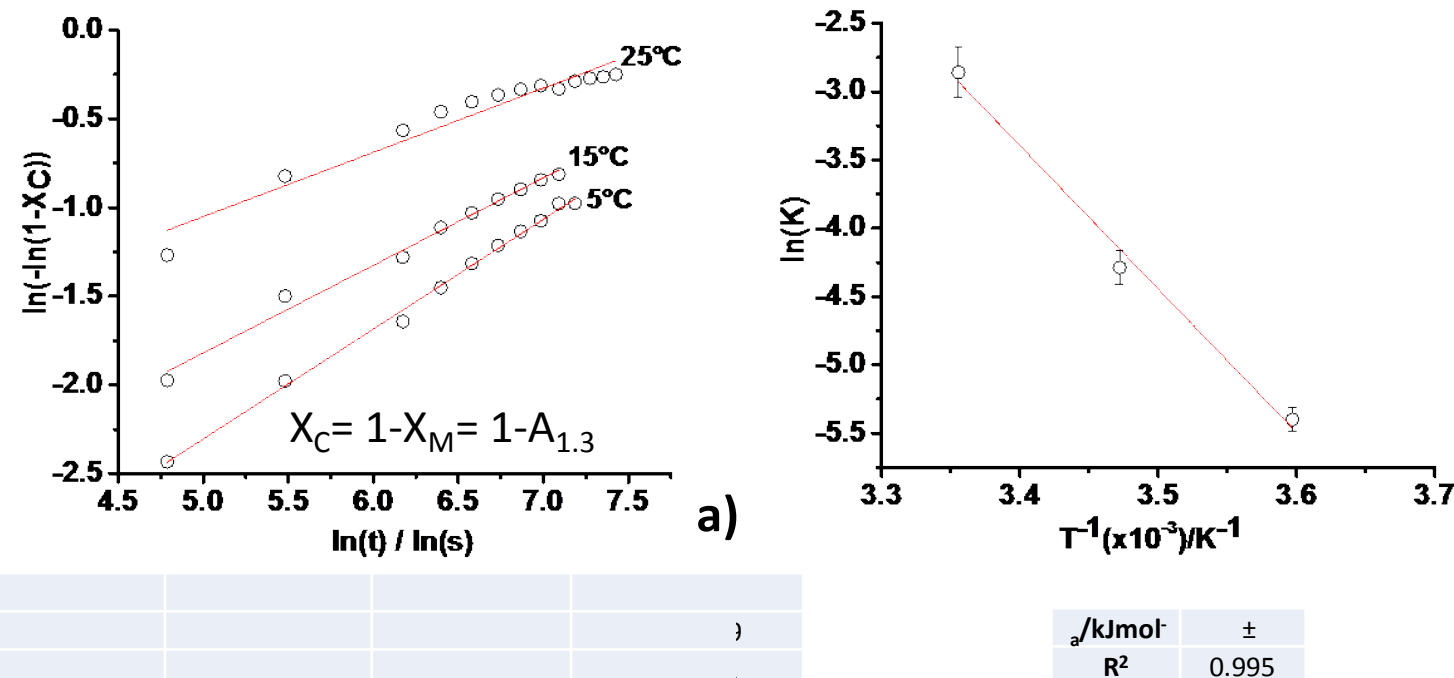

b)

Figure S 13 - a) Avrami plots for the micelle-to-fiber phase transitions corresponding to the sBola C16:0 SS at $\mathrm{C}=3 \mathrm{wt} \%$. The plots are based on the data presented in Figure $\mathrm{S} 12 \mathrm{~b}$ and they correspond to the ${ }^{1} \mathrm{H}$ NMR signal of the sBola C16:0 SS alkyl chain at $\delta=1.3 \mathrm{ppm} . X_{M}$ and $X_{F}$ are, respectively, the fraction of micelles and the fraction of fibers corresponding to the $A_{1.3}$ and [(1- $\left.\left.A_{1.3}\right)\right]$, where $A_{1.3}$ is the normalized integrated area of the NMR aliphatic peak at $\delta=1.3 \mathrm{ppm}$. b) Arrhenius plot from which the activation energy, $E_{a}$, is estimated. The Avrami plots which are used to obtain the values of $\ln (\mathbf{k})$ are given in a). 